\title{
The Effect of Various Urban Design Parameter in Alleviating Urban Heat Island and Improving Thermal Health- A Case Study in a Built Pedestrianized Block of China
}

\author{
Xuan Ma \\ chang'an university https://orcid.org/0000-0002-4042-7020 \\ Jingyuan Zhao ( $\nabla$ zjyqtt@163.com ) \\ Chang'an university \\ Lei Zhang \\ Chang'an university
}

Original article

Keywords: Thermal environment in microscale region, Urban Heat Island, PET, Thermal health

Posted Date: November 3rd, 2020

DOl: https://doi.org/10.21203/rs.3.rs-99656/v1

License: (c) (i) This work is licensed under a Creative Commons Attribution 4.0 International License.

Read Full License

Version of Record: A version of this preprint was published at Environmental Science and Pollution Research on March 17th, 2021. See the published version at https://doi.org/10.1007/s11356-021-13179z. 


\section{Abstract}

\section{Background}

Increasing urban heat island and global warming have aroused serious thermal environmental problems, even do harm to people's thermal health. Because the importance in people's daily life, Commercial pedestrianized block represents a symbol of a city or metropolis, therefore, focusing the attention on the thermal environment in such regions is very necessary. Most of the researches on urban thermal environment are calculated by remote sensing data, limited by the low spatial resolution of remote sensing image, it may not obviously reflect the true thermal environment of the research site, especially in some micro-scale regions.

Methods

Based on this, the new software ENVI-met is developed to research the thermal environment and forecast people's thermal sensation in micro-scale region.

\section{Results}

Therefore, the objective of this study aims at conducting field measurement and numerical simulation to assess the thermal environment of a typical commercial pedestrianized space in southern China, and assess the different urban design parameter in ameliorating urban heat island effect.

Conclusions

Our final results demonstrate a quantitative evidence for establishing a comprehensive standard for improving thermal environment in micro-scale region, and this study also can be a supplementary in the research field about improving thermal health.

\section{Introduction}

Under the global warming, particular urban heat island (UHI) effect remains a significant issue to tackle, which is a natural phenomenon that refers to surface and air temperature in cities are much higher than it in suburban distracts [1], this phenomenon can deteriorate urban thermal environment, what's worse, it may do harm to people's health. The research about this issue has been conducted for many years, and also has been tested for being influenced by many different factors including canyon geometry $[2,3]$, anthropogenic heat [4], thermal properties of materials [5] and urban vegetation [6-8]. In order to make a deep understand the UHI effect, the remote sensing is largely used for observing the thermal environment in urban and rural scale, most of these studies are focused on the macro-scale and urban-scale region [915], and display the distribution of air temperature and surface temperature in their research sites, thus putting forward some suggestions to decrease the air temperature. 
People's thermal sensation in summer will be affected by various parameters including people's clothing and activity, mean radiant temperature, wind speed, relative humidity, air temperature. The existing studies on macro and urban scale, limited by the low spatial resolution of remote sensing image, can't fulfil the need for evaluating people's thermal sensation and reflect the real thermal conditions in the micro-scale region such as residential community, street and so on. In order to build a suitable living environment for citizens, the research on thermal environment is changed from the macro and urban scale to the micro-scale region under the development of the technology [16]. Different from the observation of $\mathrm{UHI}$ effect on the platform of remote sensing, the study in micro-scale region is mainly relied on the software ENVI-met, which is a grid-based CFD (Computer Fluid Dynamics) three-dimensional (3D) model that can perform a micro-scale simulation in microclimate with the spatial resolution ranging between $0.5 \mathrm{~m}$ and $10 \mathrm{~m}$ within $10 \mathrm{~s}$ time[17], also it can forecast people's thermal sensation effectively. Based on the superiority in observing UHI effect in summer, ENVI-met has been widely applied in researching heat stress in micro-scale region [18-25], and its accuracy has been accepted in different climate zones.

Commercial pedestrianized block is a significant role in cities, which can not only be a symbol of a city, but also a public space for providing the citizen's life and urban tourism [26]. So, it's necessary to assess the inner microclimate and people's thermal sensation and health in such regions. Like other studies in macro and urban-scale, the researches about the microclimate and UHI effect in micro-scale region are focused on urban geometry, street orientation, vegetation and the thermal property of the paving material. In the aspect of urban geometry, the aspect ratio(H/W) and the sky view factor (SVF) are the two main factors, the former describes a proportional correlation between the height of the building and the width of the street, and the latter is an index, changing from 0 to 1 , controls the daytime solar radiation (Figure. 1). A study conducted in Brazil finds that increasing $\mathrm{H} / \mathrm{W}$ can cool down the ambient air temperature, especially in the canyon with $\mathrm{H} / \mathrm{W}$ being less than 0.5 [27], also the urban canyon with smaller SVF will obtain a higher night-time air temperature and a lower daytime air temperature $[28,29]$.

In the aspect of street orientation, a previous study in the coastal region in Israel prove that the air temperature in north-southern oriented street is $0.64^{\circ} \mathrm{Ccooler}$ than in east-western oriented street [30]. In another study, a study in semi-arid climate zone, Brazil, shows that the northeast-southwestern oriented street has the most comfortable thermal environment during the daytime [31].

In the aspect of vegetation, a previous study has been assessed that the grass can supply a cooler environment than the asphalt surface [32]. Unlike the simple grass, urban tree is measured by the size, type and arrangement of the leaves, this can be expressed by the index LAl (leaf area index)-a dimensionless data of the leaf area per unit of ground area, a series of studies have proved that tree with higher LAI will make a contribution a reduce thermal stress obviously[33-35].

In the aspect of the thermal property of ground surface, a series of studies show that the impervious paving material and the ground with higher albedo will ameliorate the heat stress effectively [36-38]. 
All mentioned parameters can reduce the heat stress in summer, however, most are discussed separately, lacking a comprehensive standard to assess the effect of various parameters in improving thermal health. Therefore, this study aims at providing a comprehensive standard for evaluating the cooling effect of different parameters in reducing UHI effect and improving people's thermal comfort and health. This study can be a supplement in the research field of outdoor thermal environment.

\section{Methodologies Of The Current Study}

It's known to us that the descriptions of urban climate are based on a single or more fixed weather stations in suburban area, unfortunately, these meteorological data can't be able to represent the whole city, especially in some micro-scale region. In order to evaluate people' thermal sensation and UHI effect accurately, recording meteorological information of the whole region simultaneously is very necessary. This work is composed of the numerical simulation and on-site measurement (Figure. 2), validating a process between on-site and the numerical results to guarantee the accuracy of the software, thus finding out the most effective strategy to ameliorate the UHI effect.

\section{Information Of This Study}

\subsection{Research site}

The Tai Zhou city is a cultural and historical city [39], which is located in southeastern part of China (Figure. 3). According to the recent meteorological information, this city is in a humid and hot climate zone, in addition, the maximum air temperature in the hottest day can be up to $38^{\circ} \mathrm{C}$ at daytime. During the hot summer, all the city is in a static-wind region, which will also lead to a worse thermal environment. As a tourism city, the Tai Zhou city attracts tourists every year [40]. The Tai Zhou Old Block is one of most tourist attractions of this city, which is a community and consist of some Chinese traditional buildings (Figure. 4).

In accordance with the respond of the local citizens and tourists, this region has some shortcomings such as the lack of shading and vegetation, the full use of harden ground and other factors, all these will badly influence the inner thermal environment [41].

\subsection{Climate conditions in Tai Zhou city}

China has a very huge land, and different regions will have various meteorological characteristics in summer. Based on the national thermal design specification of civil buildings (GB50176-93) [42], the selected city is belonged to the hot-summer and cold-winter climate zone (Figure. 5).

\subsection{On-site measurement}


In the measured days, the collected data including wind speed, air temperature and relative humidity are recorded by the fixed instruments (Table. 1). Each selected point is worked in two typical days (hottest time of the year), in addition, all the points are measured during the same time. The detailed principles are as following:

1. Each instrument is fixed at a $1.5 \mathrm{~m}$ height (average pedestrian level) from the ground.

2. Each instrument is covered by a shelter to prevent the influence on air temperature by solar radiation.

3. All used instruments are same in different points.

Based on the different geometry of the research site, this region is divided into six different points (Figure. 6 and Table. 2) [43], the measured period is carried out on July 28th and 29th, 2016. In accordance with the published weather information by the local meteorological stations, the hottest month of one year is on July, thus we choose the hottest days of this month for evaluation (Table. 3 )

The measured SVF is calculated by Ray-man by fish-eye camera, meanwhile, based on the Google maps and field survey, a simulated model including shading devices and artificial structure is built in ENVI-met to assess the simulated results. The validation process in SVF is guaranteeing the accuracy of the simulated model (Figure. 7).

\subsection{Numerical simulation}

On-site measurement in the micro-scale region lacks experimental control, while examining the using scaled models need careful design for similitude and also are too expensive. With the development of computational analysis, the numerical simulation is becoming popular. The simulation of outdoor thermal situation could be evaluated on different scales from a single or several buildings, a block, a distract to a city. In this study, the numerical model is built by the ENVI-met, which is in accordance with the SVAT model (Soil, Vegetation and Atmosphere Transfer). Also, this tool can simulate the UHI effect and microclimate conditions of the urban space with analyzing all different factors that are existed in the atmosphere integrated with buildings, vegetation, paving surface, water body and pollutant [44]. The accuracy of this software has been proved in previous studies [45-47], although, the simulated results can account for weather conditions for all scale, it's still necessary that the simulated results can be validated against on-site measurement in order to get the reliable results.

In addition, the relationship between the leaf area density (LAD) and leaf area index (LAI) is shown in equation: 
$\mathrm{LAI}=\int_{0}^{h} \mathrm{LAD}$.

$\Delta \mathrm{Z}$

(1)

In this equation, $h$ is the height of the vegetation $(m), z$ is vertical grid size. A folder of the configurations of the border tree is in accordance with the fish eye images (Figure. 8) [48].

The detailed configuration of the tree is calculated for the vegetation database of ENVI-met to

\begin{tabular}{clllllll}
\hline $\mathrm{H}(\mathrm{m} / \mathrm{s})$ & 1 & 2 & 3 & 4 & 5 & 6 & 7 \\
\hline $\mathrm{LAD}$ & 0 & 0 & 0 & 2.0 & 2.95 & 2.95 & 2.0 \\
\hline
\end{tabular}

fulfil this study (Table. 4). Also, the height of the grass is $0.25 \mathrm{~m}$, and the LAD is $0.25 \mathrm{~m} 2 / \mathrm{m} 3$.

Table. 4 LAD distribution of the selected border tree

The initial input data and boundary conditions in this study is displayed in Table. 5.

\subsection{The thermal indices}

According to the previous studies, there are a few indices that assess outdoor thermal comfort in urban environment, including Standard Effective Temperature (SET) [49],Predicted Mean Vote (PMV) [50], Physiological Equivalent (PET) [51], Universal Thermal Climate Index (UTCI) [52], Effective Temperature (ET) [53] and so on.

In this study, we choose the index PET for research, which is in accordance with energy balance of human, acknowledged to researchers as the air temperature that makes thermal conditions in indoor space in balance with the skin and core temperature in outdoor environment. In addition, it also has been evaluated as an outdoor thermal comfort index by the VDI standard of Germany. The used parameters for calculating the PET including wind velocity, relative humidity, air temperature, mean radiant temperature (MRT) and so on. Because wind velocity, relative humidity and air temperature can be easily obtained, many studies [54-56] use mentioned different parameters for a validation criterion. The simulated result can supplement on-site measurements on occasions when the instrument is lacked [57,58]. According to the previous study, the distribution of the PET values and thermal perceptions in this study is displayed in Table. 6 [59].

\section{Discussion Of This Study}




\subsection{Relationship between measured and simulated results}

In order to evaluate outdoor thermal environment, the index RMSE (root-mean-square error) is calculated for checking deviation. This index is a normally used in validating the gap between the observed and the predicted values, which is an important factor for testing the simulated results [60,61]. If this index can approach or reach 0 , the most accurate results are obtained. A lower RMSE values represent that the simulated data is closed to measured result. Figure. 10 shows the index-RMSE between the simulated and measured result.

The RMSE of air temperature in Figure.10-a shows the big deviation occurs at point -5 , reaching $3.5^{\circ} \mathrm{C}$, this may be caused by the position of the measured instruments. In order to consider the peoples' safety, the instruments are not stood in the middle of the road and instead are fixed on the sidewalks. Figure. 10b shows the big deviation also occurs at point -5 in final results of relative humidity. In the field of wind velocity (Figure. 10-c), the simulated model shows a favorable correlation with the wind velocity, with changing from 0.1 to $0.2 \mathrm{~m} / \mathrm{s}$.

Besides the calculation of the RMSE, the analysis of coefficient of determination between simulated and measured result is another very important process to assess the accuracy. A very good linear regression is found [62], as shown in Figure. 11-13, where the coefficient of determination $\left(R^{2}\right)$ of air temperature is from 0.741 to $0.9582, R^{2}$ values of relative humidity for these points range from 0.7469 to 0.9693 , and the values for wind velocity are within 0.7724 and 0.9424 . The deviation may be caused some uncertain factors during the working time. These deviations are smaller than in previous published studies [63-65]. Our final findings proved that ENVI-met tool is an accurate software to finish the task in our work.

\subsection{The new thermal environment under new cases}

As mentioned, the index PET is used for assessing people's thermal sensation. Considering the final results of numerical simulation, the thermal environment during the two measured days is shown in Figure. 14 and Figure. 15. These two figures both show that the peoples' thermal sensation during the daytime are standing 'Very hot' and 'Hot' stages in accordance with the distribution of PET values int the researched climate zone [59]. Therefore, improving outdoor thermal environment is very necessary.

Based on the previous studies, it's obvious that a stronger cooling effect will be got with a little higher background air temperature $[66,67]$, also it has proved that the positive effect of vegetation in sunny, hot days will be higher than cloudy, cold days [68], in addition, the effect of paving material with higher albedo will show a better contribution in reducing temperature in sunny days than in cloudy days [69].

In common sense, the hottest time mainly appears from 2:00pm to 4:00pm [70], in this study, the hottest period appears at 3:00pm, therefore, the PET on $3: 00 \mathrm{pm}$, Jul. 28th is selected for calculating further analysis. As Figure. 16 shows that all the selected points are suffering from a high heat stress, nearly, the hottest PET of all the points can reach $60^{\circ} \mathrm{CPET}$ at $3: 00 \mathrm{pm}$. Under this situation, it is very necessary for us to ameliorate the UHI effect and improve people's thermal sensation. 
To be mentioned, the story of the building in the commercial pedestrianized block won't be exceeded three-story, and the coverage ratio of the vegetation shouldn't be less than $25 \%$ of the total site in accordance with local design specifications [71]. The coverage ratio of different parameters in existing scenario (Base case) is shown in Figure. 17, the total building coverage ratio

occupies $55.37 \%$, in which three-story building is only $10.35 \%$. In addition, the vegetation coverage ratio just occupies $3.96 \%$. These factors can lead to a worse thermal environment in hot summer.

Based on existing scenario, new strategies are put forward. The new cases under the scientific hypothesis are shown in Table. 7.

In new cases (Figure. 18), case-1 aims at increasing grass coverage ratio to understand the cooling effect, where the coverage ratio of grass increases from $2.94 \%$ to $23.98 \%$. Like case- 1 , the coverage ratio of tree is increased to $22.06 \%$ in case- 2 and evaluate its cooling effect. In third case, replacing the ground surface in existing scenario with a new paving material with higher albedo in improving thermal safety and reducing energy cost. The last case (case-4) is through increasing

three-story building coverage ratio and building height to understand its function, where the coverage ratio of three-story building is up to $55.37 \%$.

The cooling effect of different parameters is shown as:

$\triangle \mathrm{PET}=\mathrm{PET} \otimes \mathrm{PETs}(2)$

Where PET is people' thermal sensation under existing scenario, $\mathrm{PET}_{\mathrm{S}}$ is the new thermal sensation under new cases. Upon the new cases, Figure. 19 shows that the improvement of PET appeared in the research site. The new distribution of PETs at peak time (3:00pm) has shown that the increase in tree coverage ratio (case-2) can largely change thermal environment at daytime, especially in open space (Point-1 and Point-2), in which $\triangle \mathrm{PET}$ ranges from 1.5 to $3.9^{\circ} \mathrm{C}$, meanwhile, increasing tree coverage ratio can also make a contribution to reduce PET in canyon space, where $\triangle \mathrm{PET}$ can be changed within 1.2 and $8.1^{\circ} \mathrm{C}$. This effect can be attributed to transpiration and providing shadow of the leaf at daytime. In case- 4 , increasing coverage ratio of three-story building and average building height can obviously improve thermal environment, which can be ranged from 2.1 to $12.5^{\circ} \mathrm{C} \mathrm{PET} \mathrm{in} \mathrm{canyon} \mathrm{space,} \mathrm{but} \mathrm{the} \mathrm{thermal}$ environment can't be changed too much (Point-1 and Point-2). Meanwhile, increasing grass coverage ratio can also reduce PET, but the result is limited. What's worse, changing the paving material with higher albedo (case-3) may result in a worse thermal environment in open space (Point-2), even paving material with higher albedo may cool down the ground surface, which will also reflect more solar radiation on humans' body, thus leading to

a worse PET, and the effect of grass (case-1) is not obvious.

The former results just display the distribution of the improvement of PET through synergistic effect under new cases in general. In order to provide a quantifiable effect of different parameters, a more 
detailed analysis about the cooling effect is shown in next part.

\subsection{Detailed correlation between new case and people's thermal sensation}

The whole selected block is composed of canyon space and open space. The detailed effect of new cases in open space is displayed in Figure. 20. The index $\mathrm{R}^{2}$ between different parameters and $\triangle \mathrm{PET}$ demonstrates the proportion that can be interpreted by various regression analysis. In this figure, we can find a strong positive correlation between tree coverage ratio and $\triangle \mathrm{PET}$, where it can be observed that a $5 \%$ increase will reduce $0.4^{\circ} \mathrm{C}$ PET. Meanwhile, it's obvious that an invalid correlation is found between three-story building height and $\triangle \mathrm{PET}$, with an irregular $\mathrm{R}^{2} 0.4844$, in addition, an ascension in average building height will contribute to a lower SVF and higher H/W, it's shown that the relationship between the $\mathrm{H} / \mathrm{W}$ and $\triangle \mathrm{PET}$ tends to be irregular ( $\left.\mathrm{R}^{2} \otimes 0.2971\right)$, what's worse, as SVF develops, a negative correlation between these two parameters will appear. After increasing the percentage of grass, it's found that a $5 \%$ increase in it will reduce $0.15^{\circ} \mathrm{C}$ PET. But a $3 \%$ changing with the new paving material will lead to a $0.2^{\circ} \mathrm{C}$ PET increase.

Different from the thermal environment in open space, the most essential strategy (Figure. 21) in reducing PET in canyon space is increasing coverage ratio of three-story building, in which a $10 \%$ increase in percentage of three-story building will reduce $0.5^{\circ} \mathrm{C}$ PET, in addition, a 0.1 increase in SVF will lead to increase $0.11^{\circ} \mathrm{CPET}$, while an ascension of $0.1 \mathrm{in} \mathrm{H} / \mathrm{W}$ can reduce $0.15^{\circ} \mathrm{C}$ PET at peak time. Like open space, increasing coverage ratio of tree can obviously reduce PET largely, a $5 \%$ increase will contribute to reduce $0.25^{\circ} \mathrm{C} \mathrm{PET}$ at peak time. According to the final correlation analysis of other two cases (Grass and paving

material), it's observed that the cooling effect of these two cases are limited.

In order to help local manager and policy makers understand the cooling effect of different strategy briefly. A new figure (Figure. 22) is conducted to assess the comprehensive standard.

\section{Conclusions}

The remote sensing can be used for researching UHI effect, nut it can't provide a platform for observing the thermal environment in a micro-scale region, and it also can't assess people's thermal sensation effectively. Within this study, we have finished a systematic research about UHI effect on affecting thermal environment in a commercial pedestrianized block in hot-summer and cold-winter climate zone of China. This paper is the first to display the comprehensive cooling effect of different parameter (Grass, Tree, Paving material, Building) together. As we all know, commercial pedestrianized block is an effective factor for increasing local tourism income, a better thermal environment in it will boost the vitality of the cities and attract tourists. Quantitative ENVI-met validation shows that the most significant correlation between thermal sensation and strategy is increasing tree coverage ratio $\left(R^{2} \rrbracket 0.851\right)$, where $\triangle P E T$ can be changed within 1.5 and $3.9^{\circ} \mathrm{C}$, meanwhile, the most essential strategy in improving outdoor thermal safety in canyon space is increasing coverage ratio of three-story building $\left(R^{2} \bowtie 0.9787\right)$, in which $\triangle P E T$ 
can be changed from 2.1 to $12.5^{\circ} \mathrm{C}$. Thus, the final results can provide a quantifiable standard for future research. In accordance with the final results of our study, we put forward following suggestions for designing the commercial pedestrianized block:

1. In open space, it is recommended that increasing vegetation coverage ratio is very necessary. Vegetation can't only provide shading for human, but also block solar radiation and reduce air temperature through transpiration. It is worth mentioning that moderate coverage ratio of paving material with higher albedo may improve outdoor thermal safety, but an excessive coverage ratio may cause a worse thermal environment.

2. In canyon space, based on the local design specification, increasing coverage ratio of three-story building can increase aspect ratio (H/W) and reduce SVF. Compact canyon provides a more suitable thermal environment for human, even the wind velocity in compact region is weaker than in open space, the effect of blocking solar radiation exceeds the effect of reducing wind. Moreover, most of the cities in China are in static-wind region.

The limitations of our study will be solved in the future:

1. In outdoor environment, water body is another important factor. In future study, we will also consider it in the research.

2. It is obvious that the façade material of building in the ENVI-met is presented as one, maybe this isn't existed in our world.

\section{Declarations}

Ethical Approval and Consent to participate[Not applicable

Consent for publication: Written informed consent for publication was obtained from all participants.

Availability of supporting data: The datasets used or analyzed during the current study are available from the corresponding author on reasonable request.

Competing interests: The authors declare no conflict of interest.

Funding: This research is supported by the Resilient urban and rural system planning theory and practice construction system adapting to climate change (2020TD-029), and the Ministry of Science and Technology of the People's Republic of China, under the project No. 2013FY112500, and National Natural Science Foundation of China (51678058) and the 13th-Five National S\&T Pillar Program Key Projects Sub topics (2016YFC0700401-01).

Authors' contributions: Conceptualization, Jingyuan Zhao.; methodology, Xuan Ma.; software, Zhi Cheng validation, Xuan Ma and Lei Zhang.; formal analysis, Lei Zhang.; investigation, Lei Zhang and Xuan Ma.; resources, Jingyuan Zhao.; data curation, Xuan Ma.; writing-original draft preparation, Xuan Ma and Lei 
Zhang.; writing-review and editing, Xuan Ma.; visualization, Xuan Ma; supervision, Jingyuan Zhao.; project administration, Jingyuan Zhao; funding acquisition, Jingyuan Zhao

Acknowledgments: This research was also supported by Huang Jin Zhi Engineering Education Development Foundation Of Shanghai.

\section{References}

1. R. Oke, Boundary Layer Climate, second ed., Methuen, London, 1987.

2. A, B.; S, L. Urban heat island: it's relevance in urban planning. J. Biodivers. Endanger. Species 2017, 5, 5-187.

3. Santamouris, M. Energy and Climate in the Urban Built Environment; Informa UK Limited: Colchester, UK, 2013.

4. Kolokotsa D, Psomas A, Karapidakis E. Urban heat island in southern Europe: the case study of Hania. Crete Solar Energy 2009; 83: 1871-83.

5. Wong, N.H.; Yu, C. Study of green areas and urban heat island in a tropical city. Habitat Int. 2005, 29, 547-558.

6. Tan, S.A., Fwa, T.F., 1992. Influence of pavement materials on the thermal environment of outdoor spaces. Build. Environ. 27 (3), 289-295.

7. Tan, C.L.,Wong, N.H., Jusuf, S.K., 2013. Outdoor mean radiant temperature estimation in the tropical urban environment. Build. Environ. 64, 118-129.

8. Shashua-Bar, L., Tsiros, I.X., Hoffman,M., 2012. Passive cooling design options to amelioratethermal comfort in urban streets of a Mediterranean climate (Athens) under hot summer conditions. Build. Environ. 57, 110-119

9. Ferdous Jannatul, R.T. Temporal Dynamics and Relationship of Land Use Land Cover and Land Surface Temperature in Dhaka. In Proceedings of the 4th International Conference on Civil Engineering for Sustainable Development (ICCESD 2018), KUET, Khulna, Bangladesh, 9-11 February 2018.

10. Alobeid, A.; Jacobsen, K.; Heipke, C. Comparison of matching algorithms for DSM generation in urban areasfrom Ikonos imagery. Photogramm. Eng. Remote Sens. 2010, 76, 1041-1050.

11. Avtar, R.; Sawada, H. Use of DEM data to monitor height changes due to deforestation. Arab. J. Geosci. 2012, 6, 4859-4871.

12. Buyantuyev, A.;Wu, J. Urban heat islands and landscape heterogeneity: linking spatiotemporal variations in surface temperatures to land-cover and socioeconomic patterns. Landsc. Ecol. 2009, 25, 17-33.

13. Arnfield, A.J. Two decades of urban climate research: a review of turbulence, exchanges of energy and water, and the urban heat island. Int. J. Clim. 2003, 23, 1-26. 
14. Grover, A.; Singh, R. Analysis of urban heat island (UHI) in relation to normalized difference vegetation index (NDVI): A comparative study of Delhi and Mumbai. Environ. 2015, 2, 125-138.

15. Ramaiah, M.; Avtar, R. Urban green spaces and their need in cities of rapidly urbanizing India: A review. Urban Sci. 2020, 3, 94.

16. Changwang Z. Simulation of urban micro-scale environment based on ENVI-met[D]. Shandong architecture school. 2019.

17. Huttner, S., Bruse,M., 2009. Numerical modeling of the urban climate-a preview on ENVI-met 4.0. Proceedings of the 7th International Conference on Urban Climate, Yokohama, Japan, pp. 3-7.

18. Yamada, T., Mellor, G., 1975. A simulation of the Wangara atmospheric boundary layer data. J. Atmos. Sci. 32 (12), 2309-2329.

19. Fang, X., Jiang, W., Miao, S., Zhang, N., Xu, M., Ji, C., Chen, X., Wei, J., Wang, Z., Wang, X., 2004. The multi-scale numerical modeling system for research on the relationship between urban planning and meteorological environment. Adv. Atmos. Sci. 21 (1), 103-112.

20. Oliveira, S., Andrade, H., Vaz, T., 2011. The cooling effect of green spaces as a contribution to the mitigation of urban heat: a case study in Lisbon. Build. Environ. 46 (11), 2186-2194.

21. Toparlar, Y., Blocken, B., Maiheu, B., Van Heijst, G.J.F., 2017. A review on the CFD analysis of urban microclimate. Renew. Sust. Energ. Rev. 80, 1613-1640.

22. Rosso, F., Golasi, I., Castaldo, V.L., Piselli, C., Pisello, A.L., Salata, F., Ferrero, M., Cotana, F., de Lieto Vollaro, A., 2018. On the impact of innovative materials on outdoor thermal comfort of pedestrians in historical urban canyons. Renew. Energy 118, 825-839.

23. Andrade, H., Alcoforado, M.J., 2008. Microclimatic variation of thermal comfort in a district of Lisbon (Telheiras) at night. Theor. Appl. Climatol. 92, 225-237.

24. Wang, Y., Akbari,H., 2014. Effect of sky view factor on outdoor temperature and comfort in Montreal. Environ. Eng. Sci. 31 (6), 272-287.

25. Wang, Y., Akbari, H., 2016. The effects of street tree planting on urban heat island mitigation in Montreal. Sustain. Cities Soc. 27, 122-128.

26. Xuan Ma, Hiroatsu Fukuda, Dian Zhou, Weijun Gao, Mengying Wang, The study on outdoor pedestrian thermal comfort in blocks: A case study of the Dao He Old Block in hot-summer and coldwinter area of southern China, Solar Energy, 179, 2019, 210-225

27. Akbari, H., Levinson, R., 2008. Evolution of cool-roof standards in the US. Adv. Build. Energy Res. 2, $1-32$.

28. Svensson, M.K., 2004. Sky view factor analysis-implications for urban air temperature differences. Meteorol. Appl. 11, 201-211.

29. Unger, J., 2004. Intra-urban relationship between surface geometry and urban heat island: review and new approach. Climate Res. 27, 253-264.

30. Shashua-Bar, L., Pearlmutter, D., Erell, E., 2011. The influence of trees and grass onoutdoor thermal comfort in a hot-arid environment. Int. J. Climatology 31, 1498-1506. 
31. Abreu-Harbich, L.V., Labaki, L.C., Matzarakis, A., 2013. Thermal bioclimate inidealized urban street canyons in Campinas, Brazil. Theor. Appl. Climatol., 1-8.

32. Yang, F., Qian, F., Lau, S., 2013. Urban form and density as indicators for summertime outdoor ventilation potential: a case study on high-rise housing in Shanghai. Build. Environ. 70, 122-137.

33. Lee, H., Holst, J., Mayer, H., 2013. Modification of human-biometeorologically significant radiant flux densities by shading as local method to mitigate heat stress in summer within urban street canyons. Adv. Meteorol. 2013, 1-13.

34. Duarte, D.H., Shinzato, P., dos Santos Gusson, C., Alves, C.A., 2015. The impact of vegetation on urban microclimate to counterbalance built density in a subtropical changing climate. Urban Clim. $14,224-239$.

35. Wong, N.H., Jusuf, S.K., 2010. Study on the microclimate condition along a green pedestrian canyon in Singapore. Archit. Sci. Rev. 53 (2), 196-212.

36. Li, H., 2013. Evaluation of Cool Pavement Strategies for Heat Island Mitigation. (Ph.D. Thesis). University of California, Davis, Davis, United States.

37. Li, H., He, Y., Harvey, J., 2016. Human thermal comfort: modeling the impact of different cool pavement strategies. Transp. Res. Rec. 2575, 92-102.

38. Li, K., Zhang, Y., Zhao, L., 2016. Outdoor thermal comfort and activities in the urban residential community in a humid subtropical area of China. Energ. Buildings 133, 498-511.

39. Government of Tai Zhou. http://www.taizhou.gov.cn/. (Available on line on April, 2020).

40. Tourism organization of Tai Zhou. http://lyj.taizhou.gov.cn/. (Available on line on April, 2020).

41. The organization of Tai Zhou old street. http://wgxj.taizhou.gov.cn/.(Available on line on April, 2020).

42. Thermal Design Code for Civil Buildings, GB 50176-51993, Ministry of Housing and Urban-rural Development of the People's Republic of China, Beijing, China, (1993).

43. Xuan Ma, Hiroatsu Fukuda, Dian Zhou, Mengying Wang. Study on outdoor thermal comfort of the commercial pedestrian block in hot-summer and cold-winter region of southern China-A case study of The Taizhou Old Block. Tourism management, 79, 2019, 186-205.

44. Bruse, ENVI-met, 4, 2014. http://www.ENVI-met.info.

45. Srivanit M, Hokao K. Evaluating the cooling effects of greening for improving the outdoor thermal environment at an institutional campus in the summer. Build Environ 2013; 66:158-72.

46. Alexandri E, Jones P. Temperature decreases in an urban canyon due to green walls and green roofs in diverse climates. Build Environ 2008; 43:480-93.

47. Vidrih B, Medved S. Multiparametric model of urban park cooling island. Urb Forest Urb Greening 2013; 12: 220-9.

48. Bowler DE, Buyung-Ali L, Knight TM, Pullin AS. Urban greening to cool towns and cities: a systematic review of the empirical evidence. Landscape Urb Plann 2010; 97:147-55.

49. Fanger Po. Thermal comfort. New York: McGraw Hill; 1972 
50. Gagge AP, Fobelets AP, Berglund LG. A standard predictive index of human respond to the thermal environment. ASHARE Transaction 1986; 92: 709-31.

51. Spagnolo J, de Dear RJ. A field study of thermal comfort in outdoor and semi-outdoor environments in subtropical Sydney Australia. Building and Environment 2003; 38:721-38.

52. Höppe.The physiological equivalent temperature - a universal index for the bio-meteorological assessment of the thermal environment. International Journal of Biometeorology, 1999, 43 (2):71.

53. Rosso, F., Pisello, A.L., Cotana, F., Ferrero, M., 2016. On the thermal and visual pedestrians' perception about cool natural stones for urban paving: a field survey in summer conditions. Build. Environ. 107, 198-214.

54. Rosso, F., Pisello, A.L., Cotana, F., Ferrero, M., 2016. On the thermal and visual pedestrians'perception about cool natural stones for urban paving: a field survey in summer conditions. Build. Environ. 107, 198-214.

55. Rosso, F., Golasi, I., Castaldo, V.L., Piselli, C., Pisello, A.L., Salata, F., Ferrero, M., Cotana, F., de Lieto Vollaro, A., 2018. On the impact of innovative materials on outdoor thermal comfort of pedestrians in historical urban canyons. Renew. Energy 118, 825-839.

56. Saaroni, H., Ziv, B., 2003. The impact of a small lake on heat stress in a Mediterranean urban park: the case of Tel Aviv, Israel. Int. J. Biometeorol. 47 (3), 156-165.

57. Liu, J., Niu, J., Xia, Q., 2016. Combining measured thermal parameters and simulated wind velocity to predict outdoor thermal comfort. Build. Environ. 105, 185-197.

58. Liu, W., Zhang, Y., Deng, Q., 2016. The effects of urban microclimate on outdoor thermal sensation and neutral temperature in hot-summer and cold-winter climate. Energ. Buildings 128, 190-197.

59. Weiwei Liu, Yingxia Zhang, Qihong Deng, The effects of urban microclimate on outdoor thermal sensation and neutral temperature in hot-summer and cold-winter climate, Energy and Buildings, 2016, 190-197.

60. Willmott, C.J., 1981. On the validation of models. Phys. Geography 2, 184-194.

61. Willmott, C.J., 1982. Some comments on the evaluation of model performance. Bull. Am. Meteorological Soc. 63, 1309-1313.

62. E. Morakinyo, L. Kong, K.K.-L. Lau, C. Yuan, E. Ng, A study on the impact of shadow-cast and tree species on in-canyon and neighborhood's thermal comfort, Build. Environ. 115 (2017) 1-17.

63. Qaid, H.B. Lamit, D.R. Ossen, R.N.R. Shahminan, Urban heat island and thermal comfort conditions at micro-climate scale in a tropical planned city, Energy Build. 133 (2016) 577-595.

64. Park, M., Hagishima, A., Tanimoto, J., Narita, K.I., 2012. Effect of urban vegetation on outdoor thermal environment: field measurement at a scale model site. Build. Environ. 56, 38-46.

65. Syafii, N.I., Ichinose, M., Kumakura, E., Jusuf, S.K., Chigusa, K., Wong, N.H., 2017. Thermal environment assessment around bodies of water in urban canyons: a scale model study. Sustain. Cities Soc. 34, 79-89. 
66. Shashua-Bar, L., Hoffman,M.E., 2000. Vegetation as a climatic component in the design of an urban street: an empirical model for predicting the cooling effect of urban green areas with trees. Energ. Buildings 31 (3), 221-235.

67. Shashua-Bar, L., Potchter, O., Bitan, A., Boltansky, D., Yaakov, Y., 2010. Microclimate modelling of street tree species effects within the varied urban morphology in the Mediterranean city of Tel Aviv, Israel. Int. J. Climatol. 30 (1), 44-57.

68. Wong, N.H., Chen, Y., Ong, C.L., Sia, A., 2003. Investigation of thermal benefits of rooftop garden in the tropical environment. Build. Environ. 38 (2), 261-270.

69. Yang, J., Wang, Z.H., Kaloush, K.E., Dylla, H., 2016. Effect of pavement thermal properties on mitigating urban heat islands: a multi-scale modeling case study in Phoenix. Build. Environ. 108, $110-121$.

70. Ma, X.; Fukuda, H.; Zhou, D.; Wang, M. The Evaluation of Outdoor Thermal Sensation and Outdoor Energy Efficiency of a Commercial Pedestrianized Zone. Energies 2019, 12, 1324.

71. The commercial building design specification. Available on line at: https://wenku.baidu.com/view/.html; 2019.

\section{Tables}

Due to technical limitations, table 1, 2, 3, 4, 5, 6 and 7 is only available as a download in the Supplemental Files section.

\section{Figures}




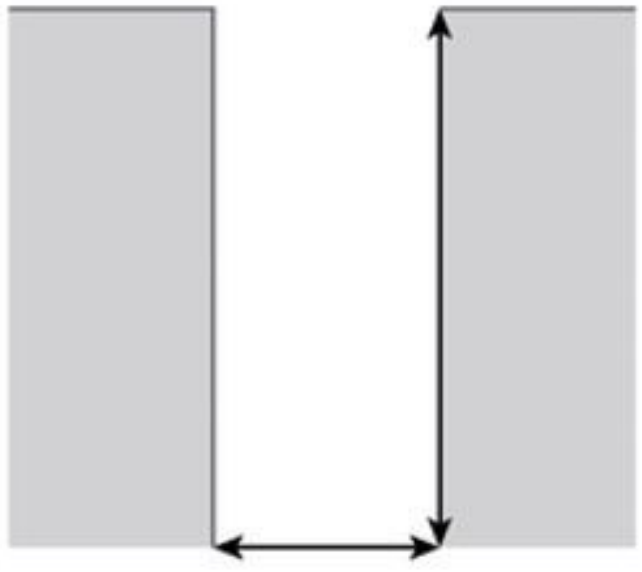

aspect ratio (H/W)

Figure 1

Urban geometry in canyon space

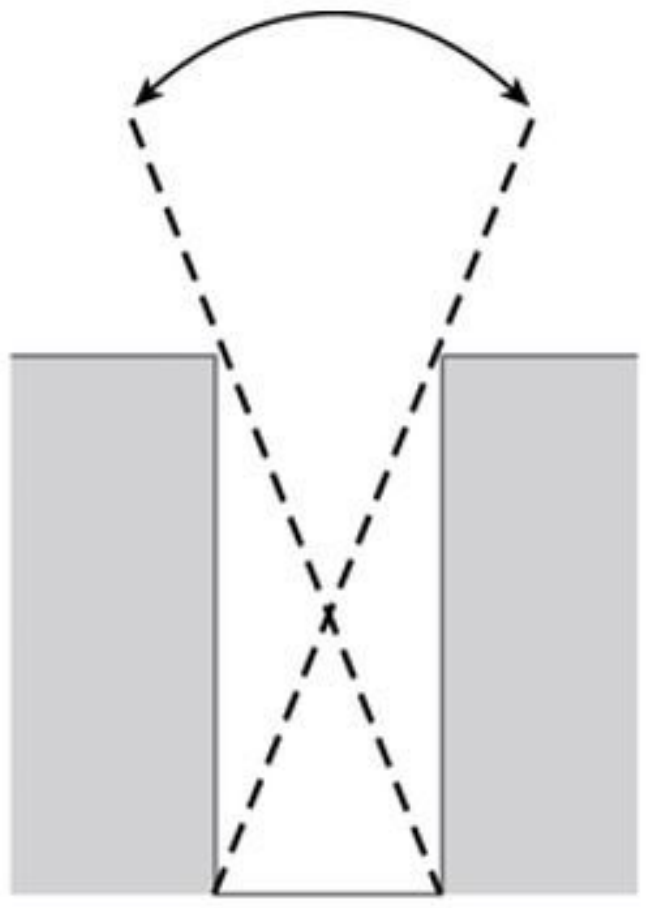

sky view factor 


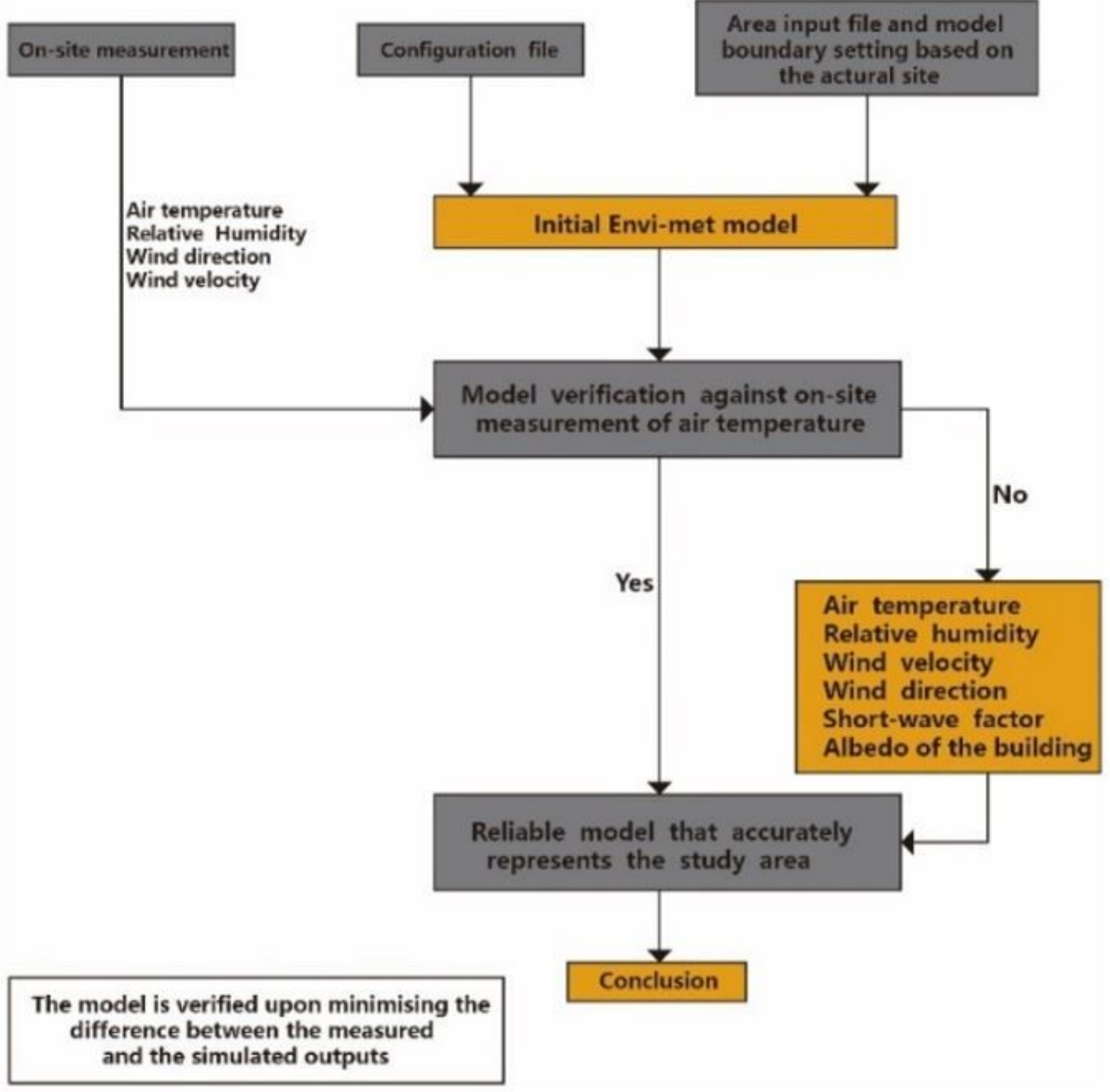

Figure 2

Methodological framework of this study 


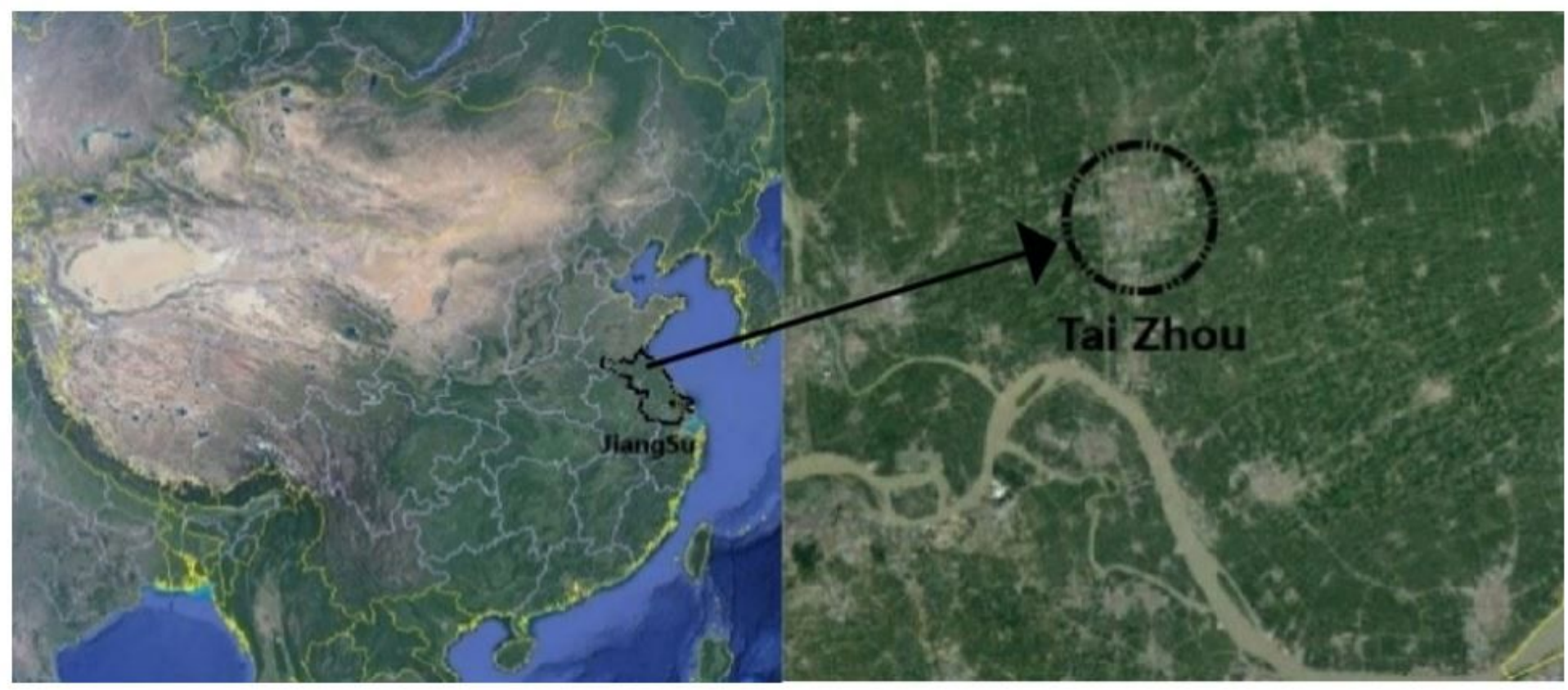

\section{Figure 3}

The site of the Tai Zhou city on Google map Note: The designations employed and the presentation of the material on this map do not imply the expression of any opinion whatsoever on the part of Research Square concerning the legal status of any country, territory, city or area or of its authorities, or concerning the delimitation of its frontiers or boundaries. This map has been provided by the authors.

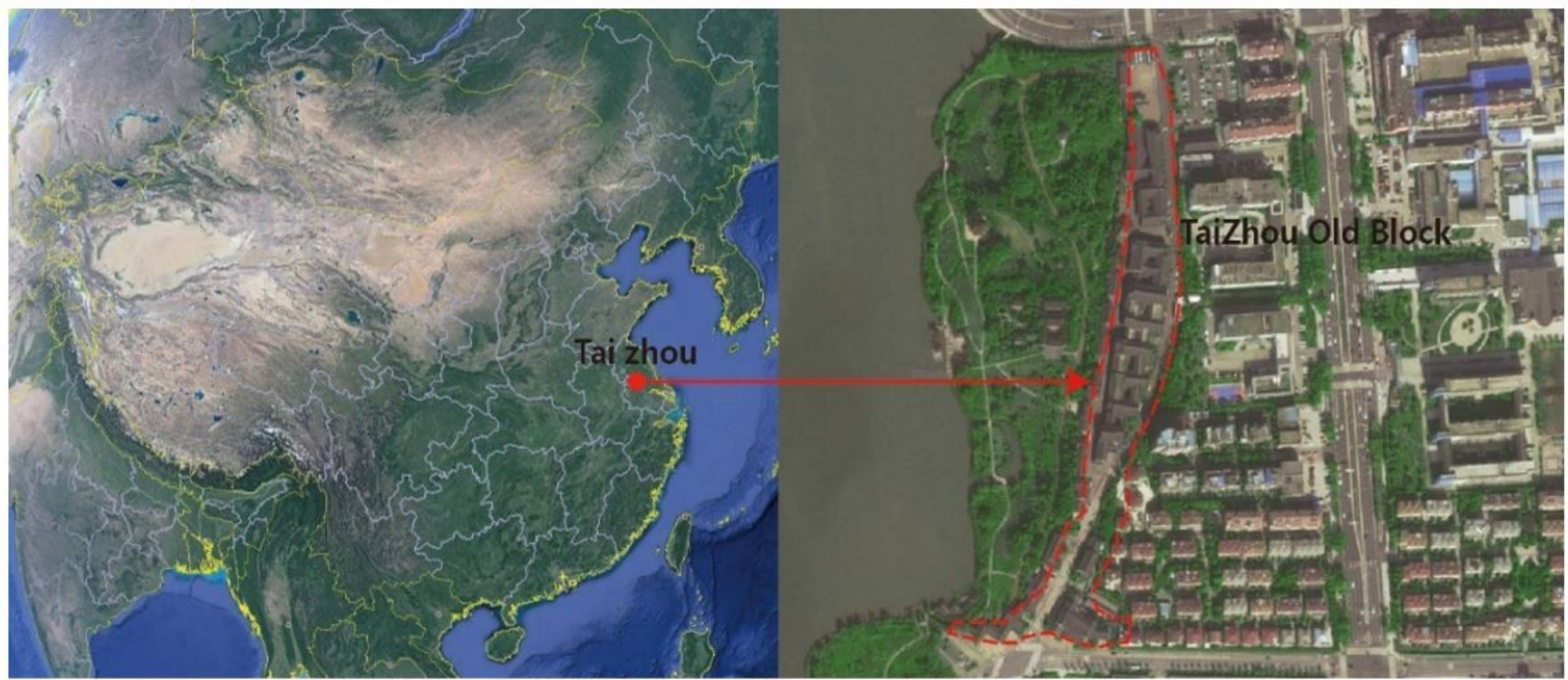

\section{Figure 4}

The site of the selected site (Tai Zhou Old block) Note: The designations employed and the presentation of the material on this map do not imply the expression of any opinion whatsoever on the part of 
Research Square concerning the legal status of any country, territory, city or area or of its authorities, or concerning the delimitation of its frontiers or boundaries. This map has been provided by the authors.

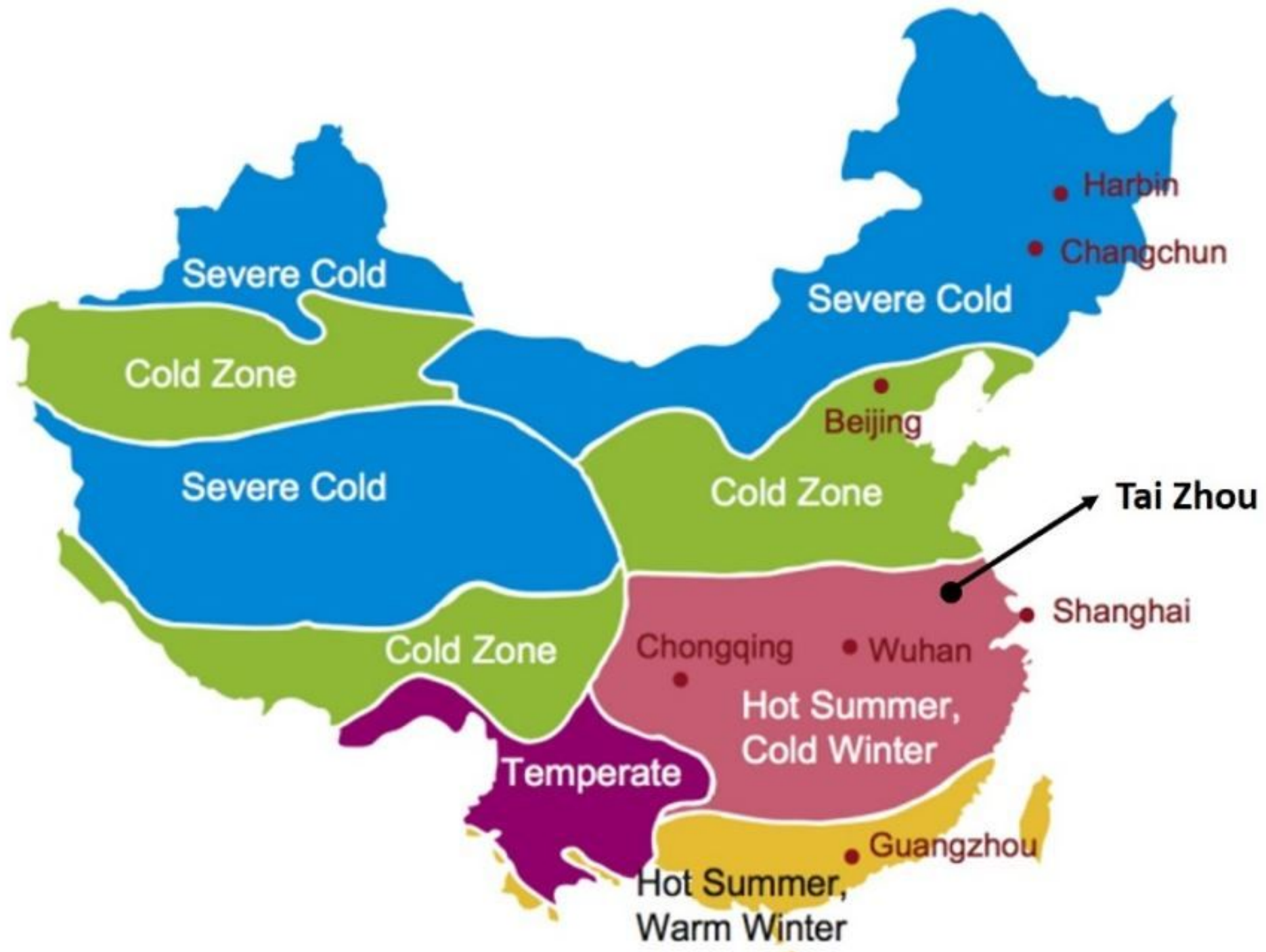

\section{Figure 5}

The national thermal design specification of civil buildings of China Note: The designations employed and the presentation of the material on this map do not imply the expression of any opinion whatsoever on the part of Research Square concerning the legal status of any country, territory, city or area or of its authorities, or concerning the delimitation of its frontiers or boundaries. This map has been provided by the authors. 


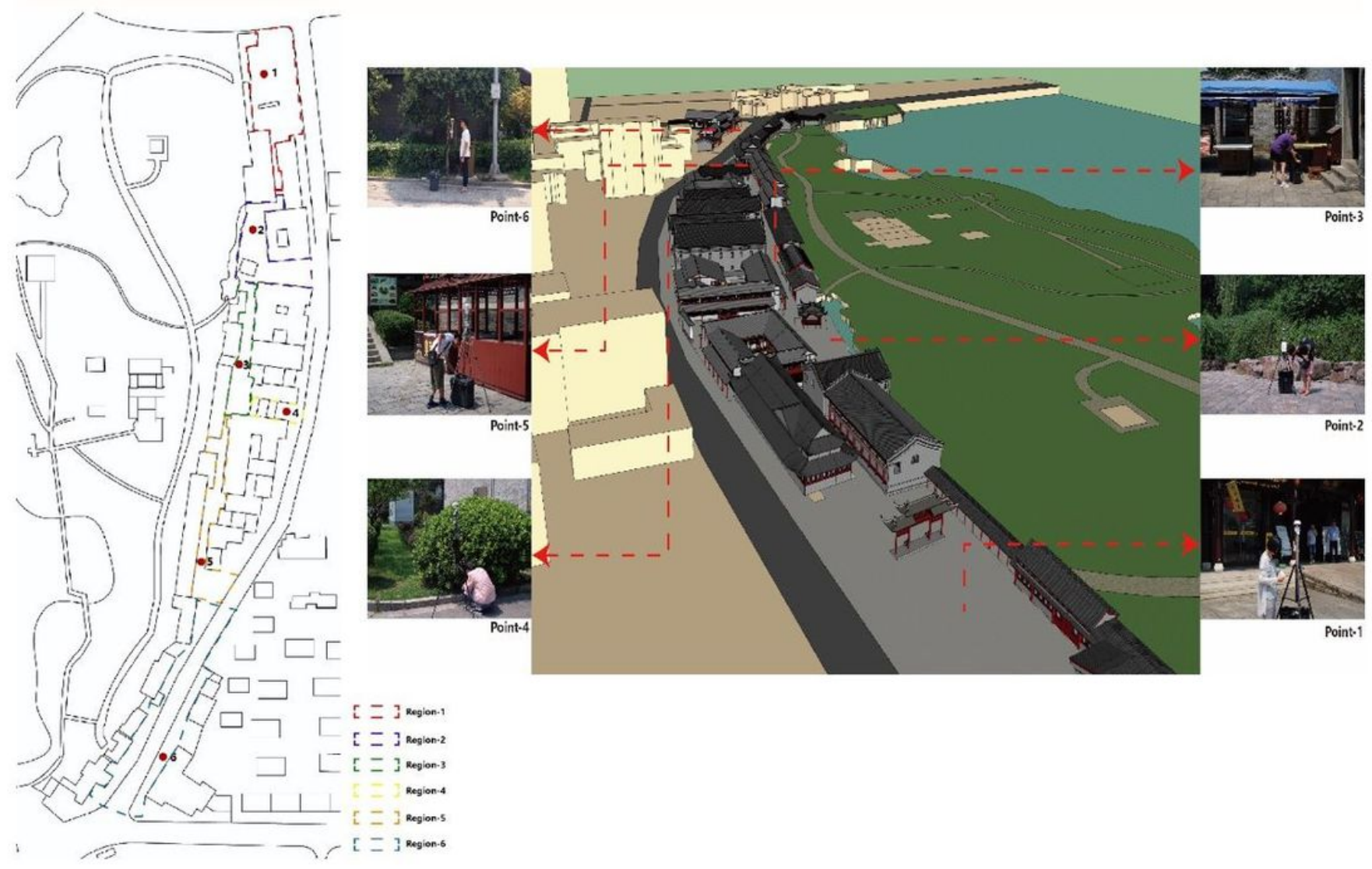

Figure 6

The different points in this study [43] 


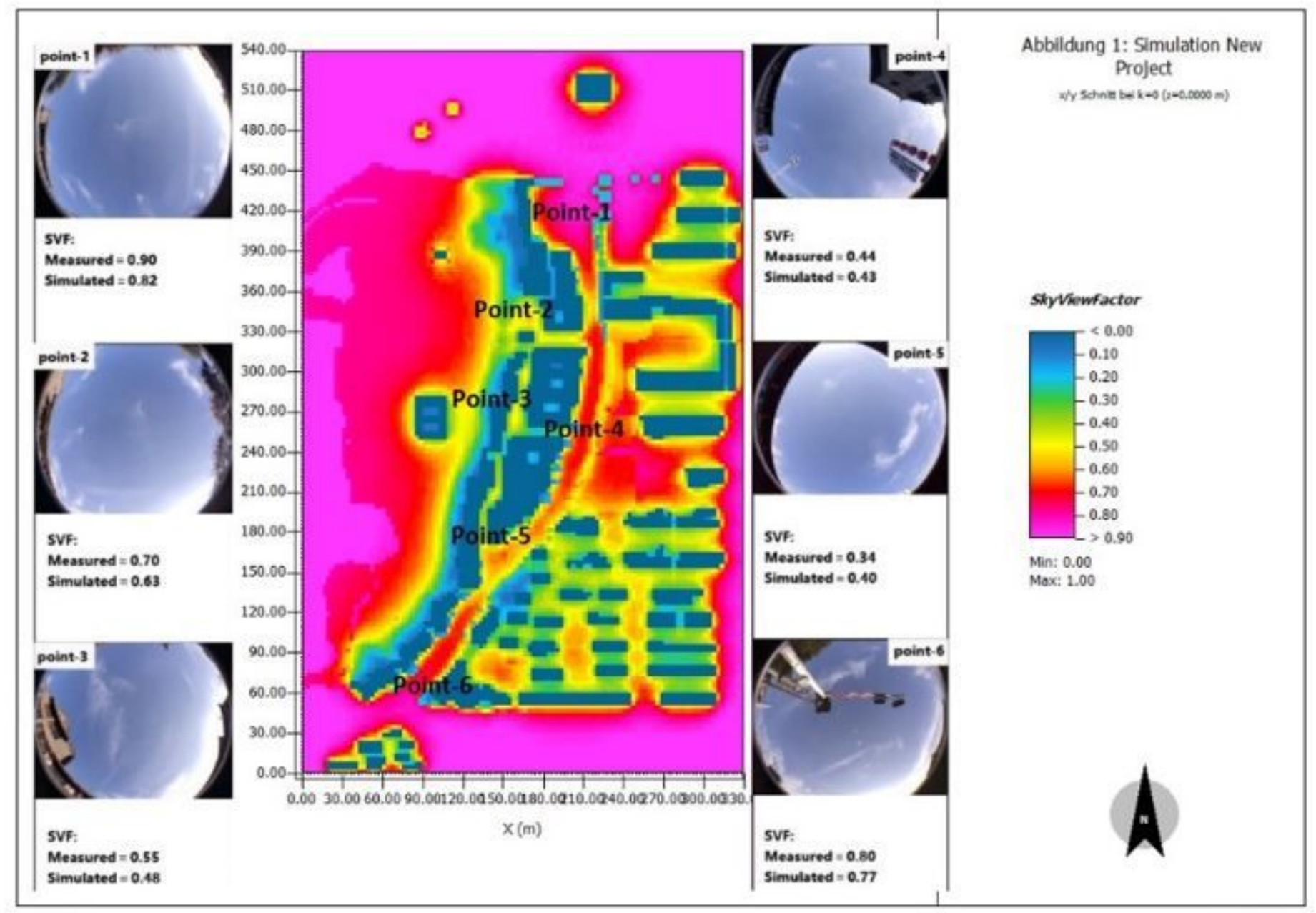

Evi_net

Figure 7

The validation between measured and simulated SVF [43] 

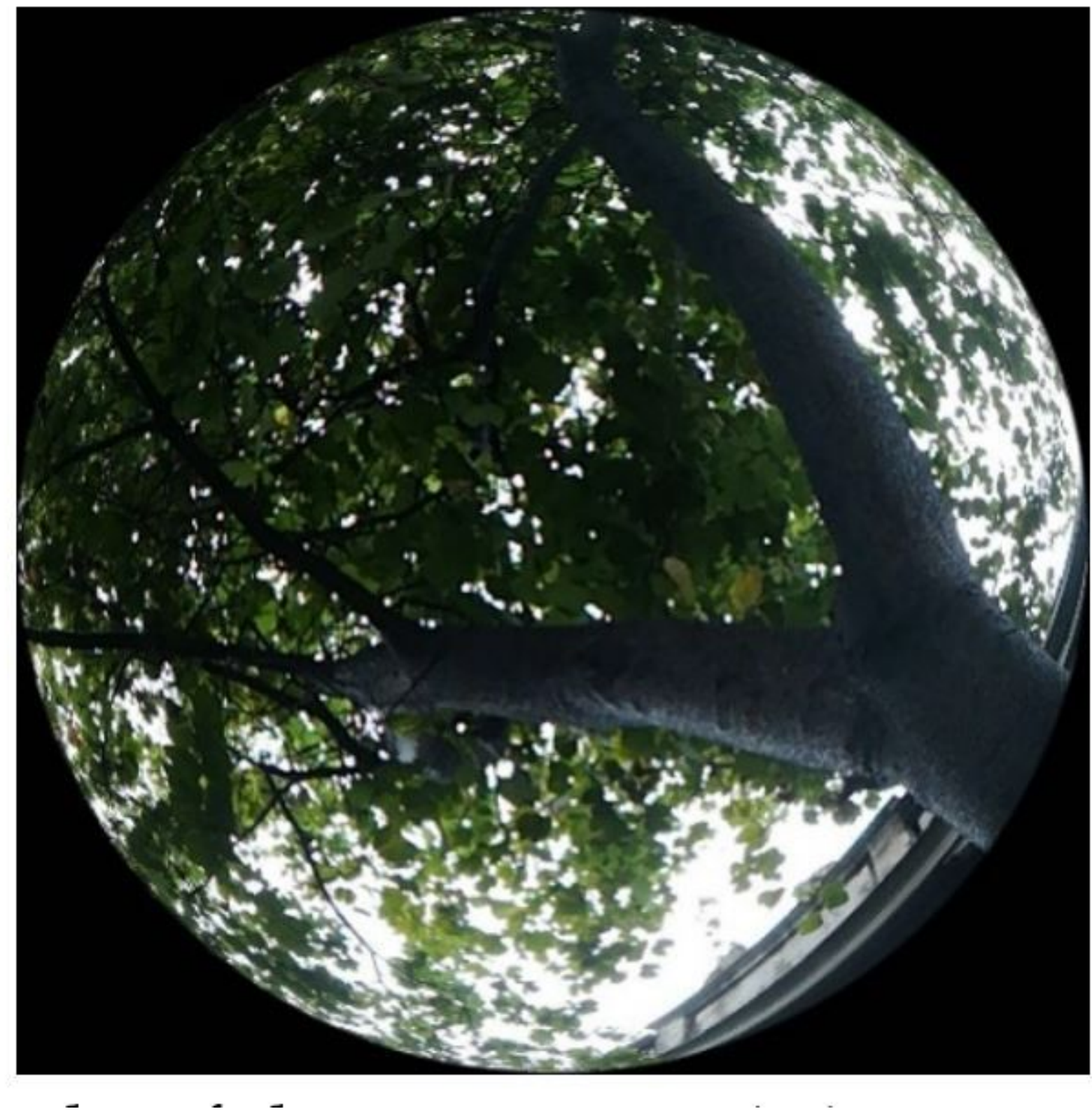

Figure 8

The fisheye image of the measured tree [43] 


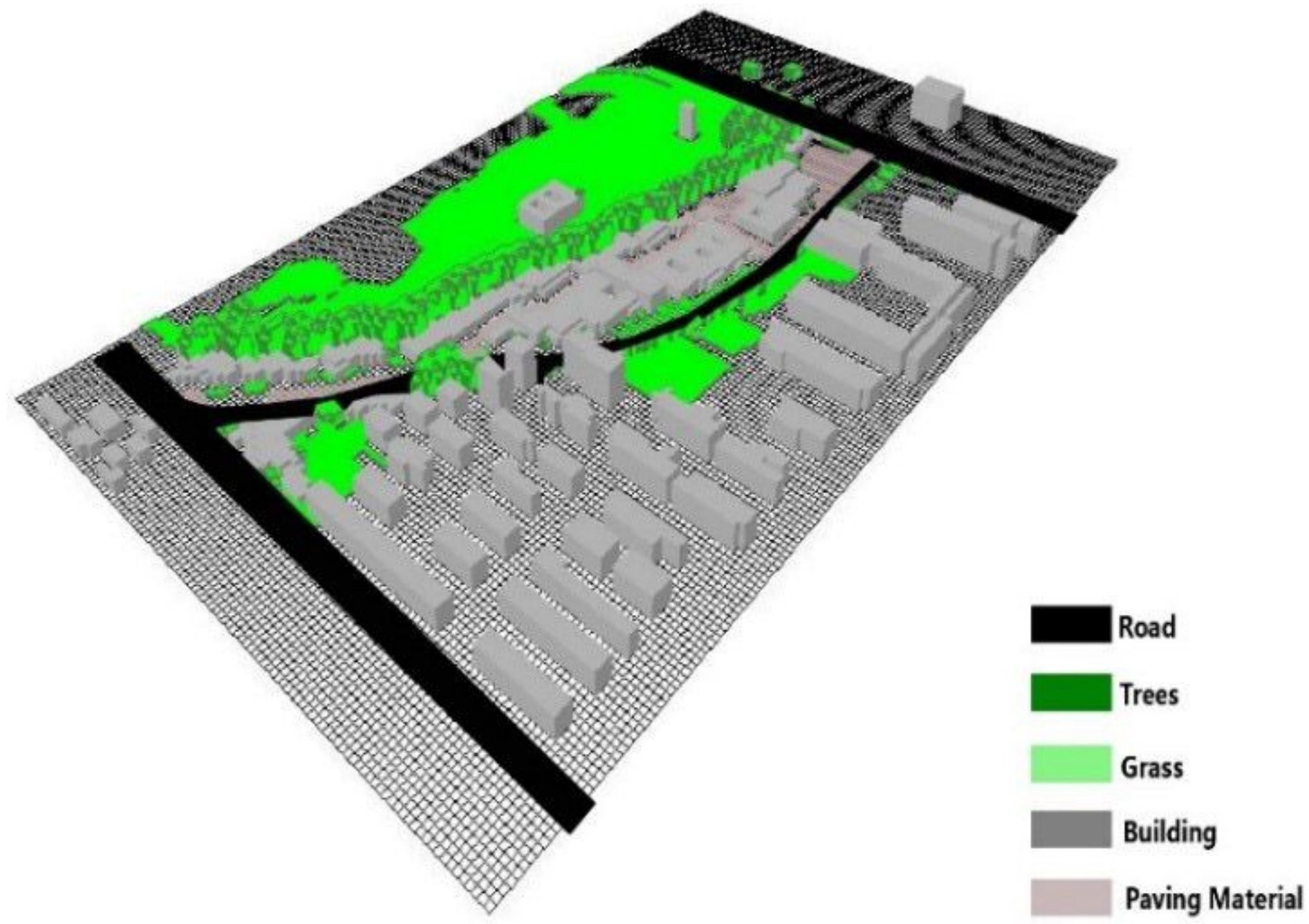

Figure 9

The built model in ENVI-met of this study 


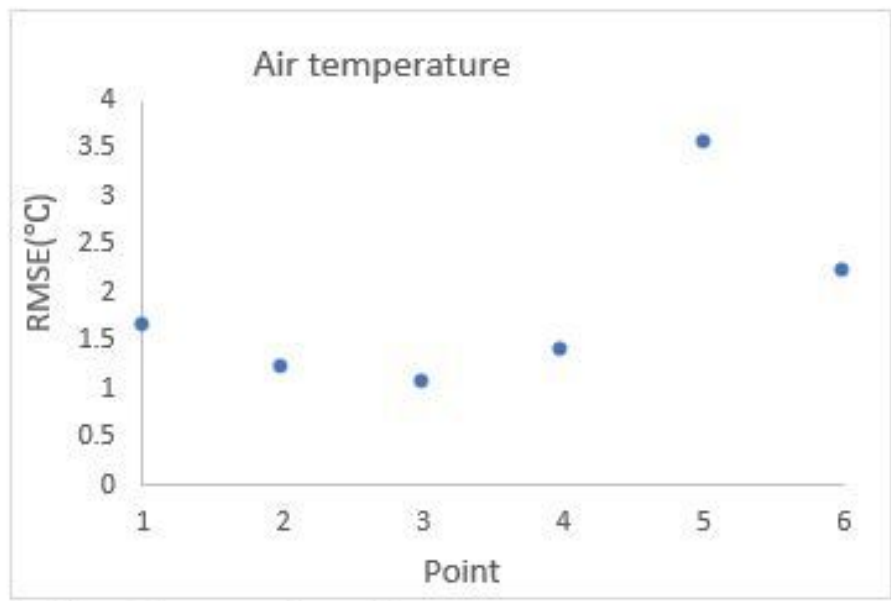

between the simulated and measured result.

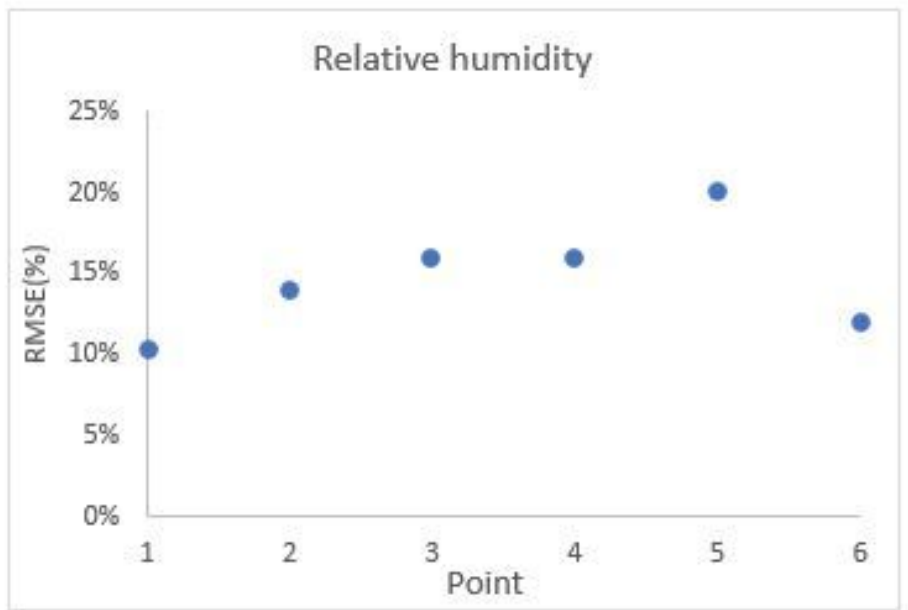

(a)

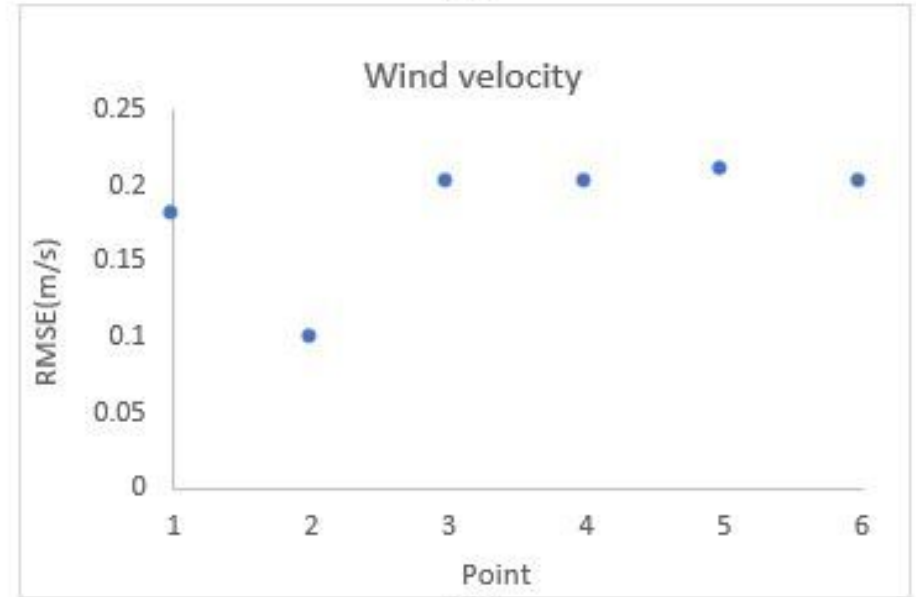

(b)

(c)

Figure 10

RMSE between measured and measured data 

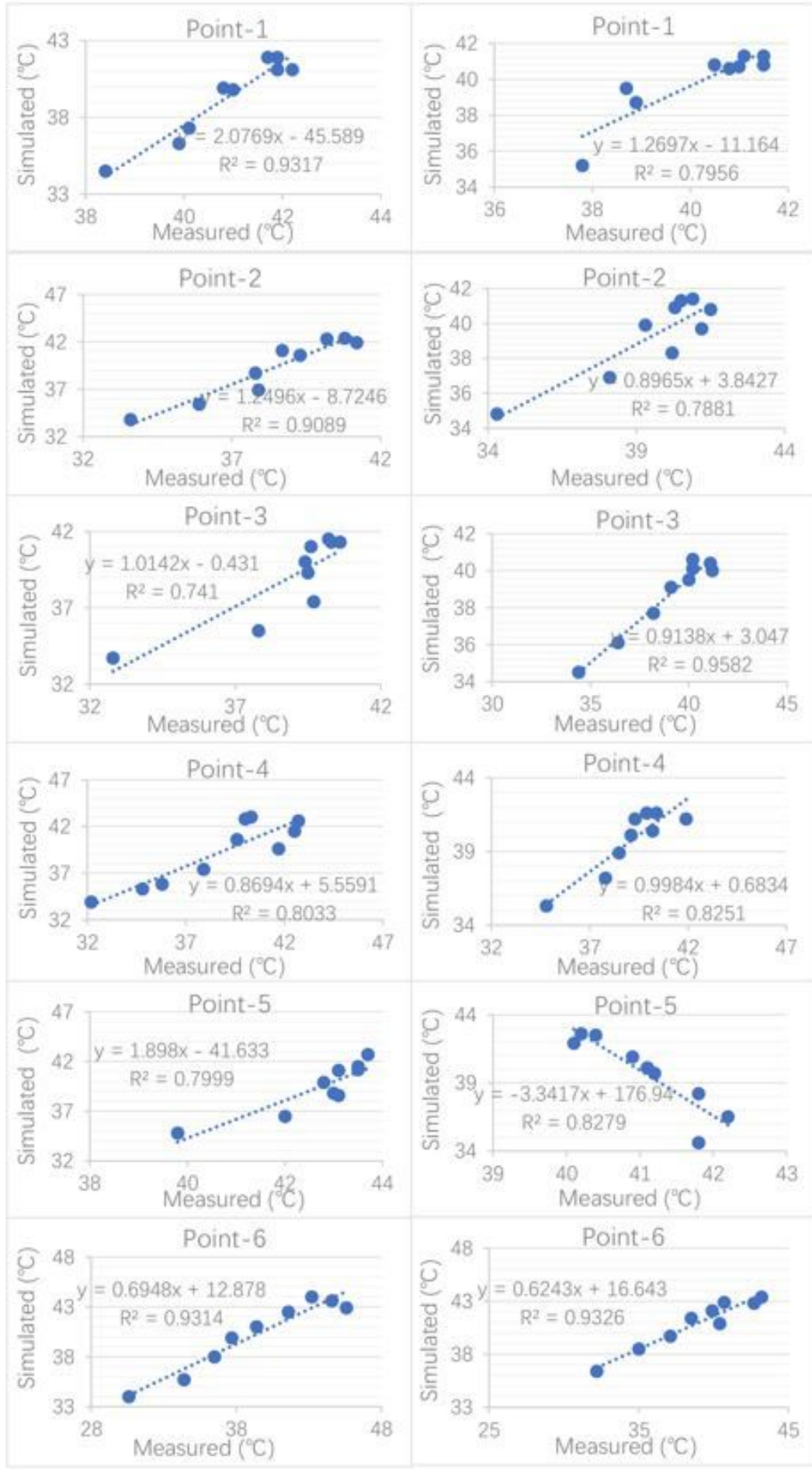

\section{Figure 11}

Correlation between measured and simulated air temperature [43] 

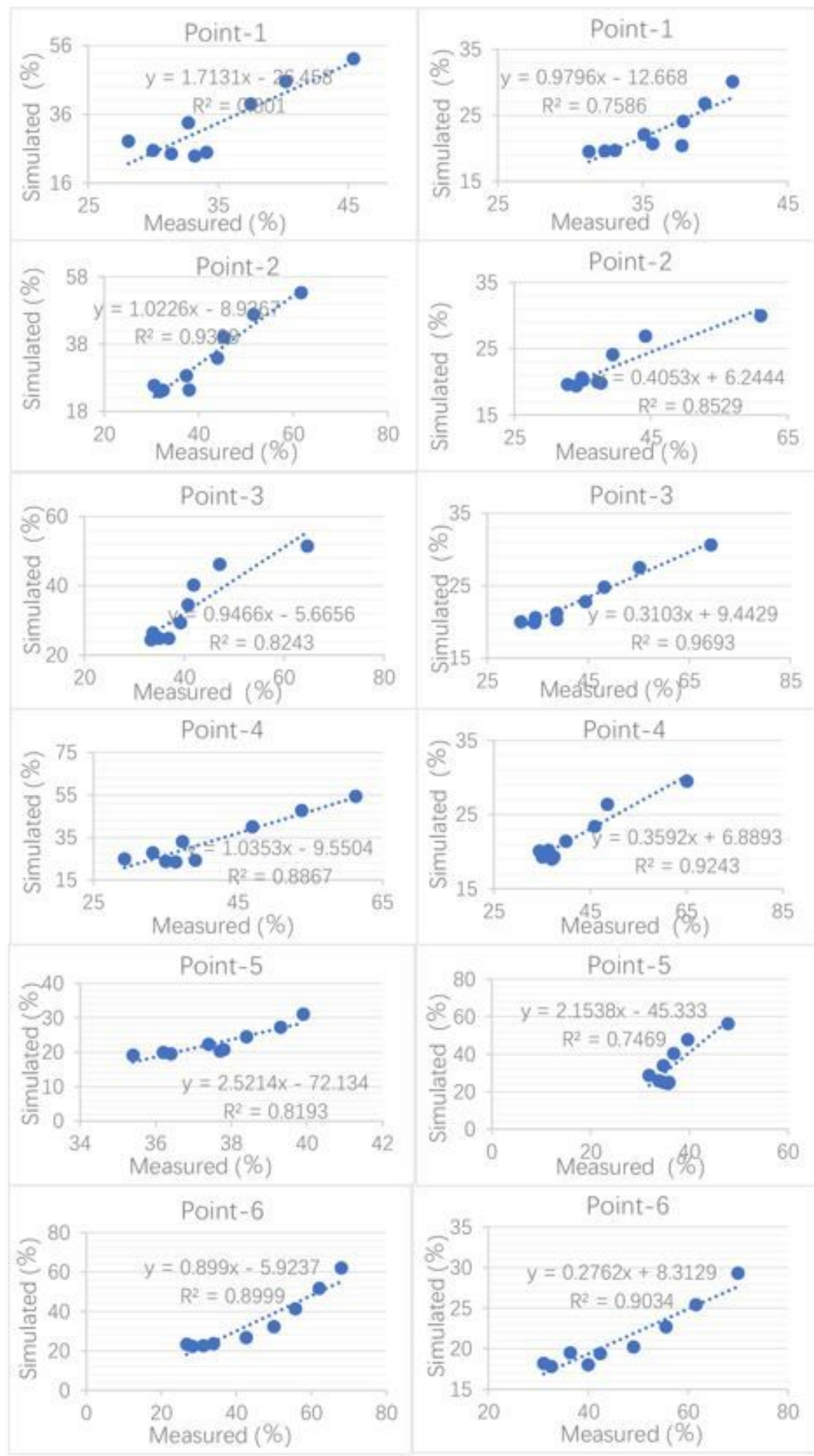

\section{Figure 12}

Correlation between measured and simulated relative humidity [43] 


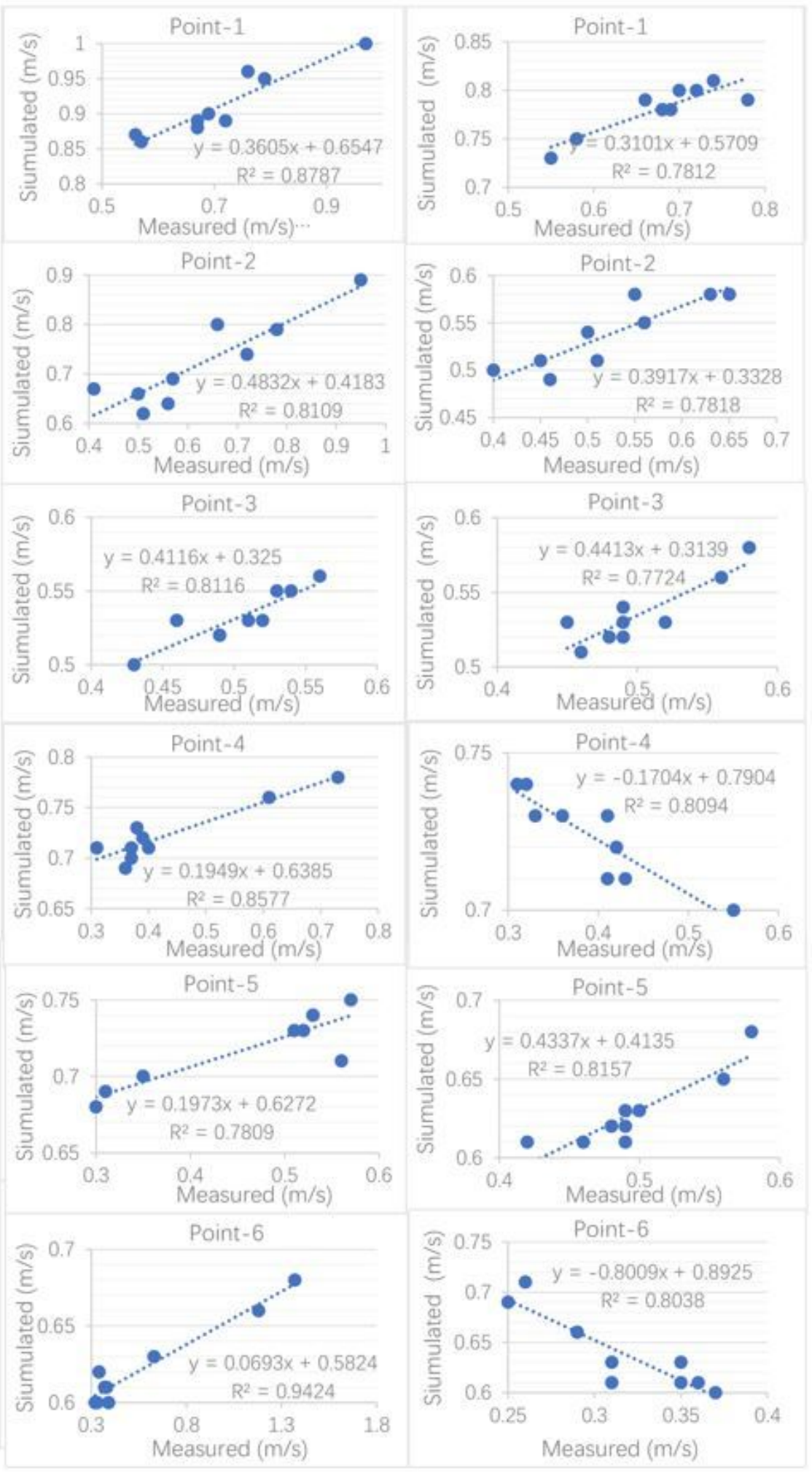

Figure 13

Correlation between measured and simulated wind velocity [43] 


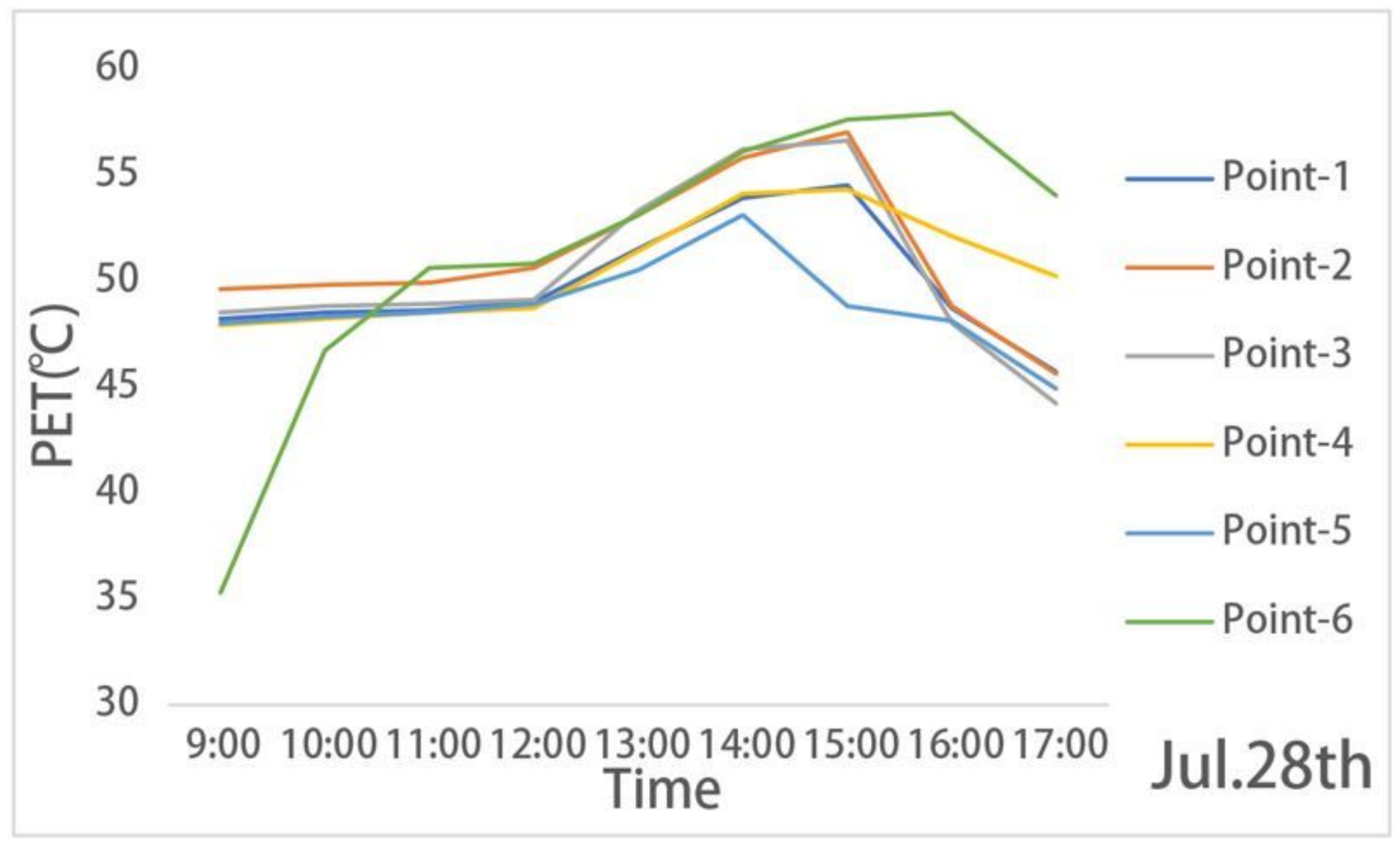

Figure 14

The PET of existing scenario on Jul. 28th 


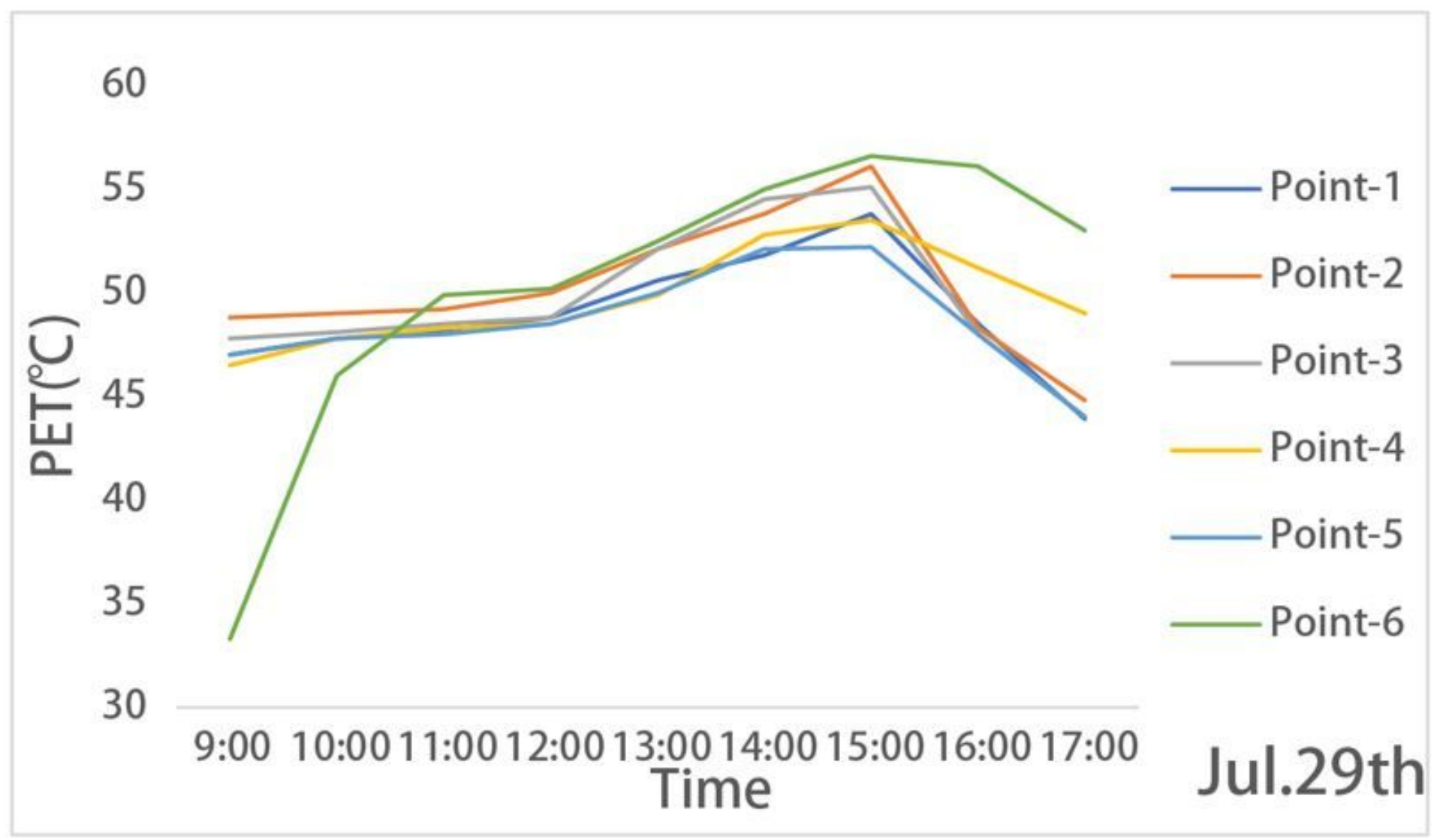

Figure 15

The PET of existing scenario on Jul. 29th 

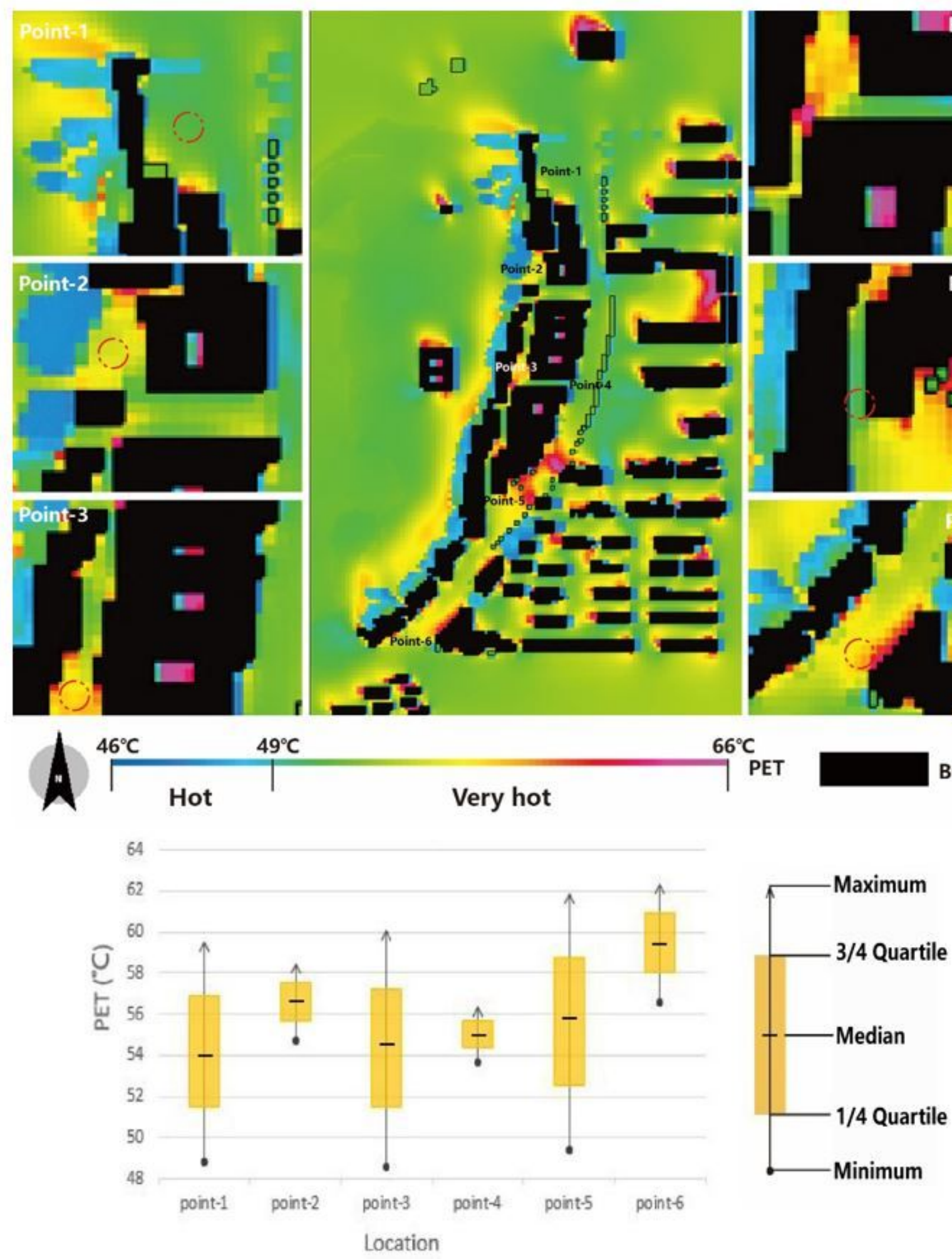

Figure 16

The PET values of the site at 3:00pm on Jul.28th 


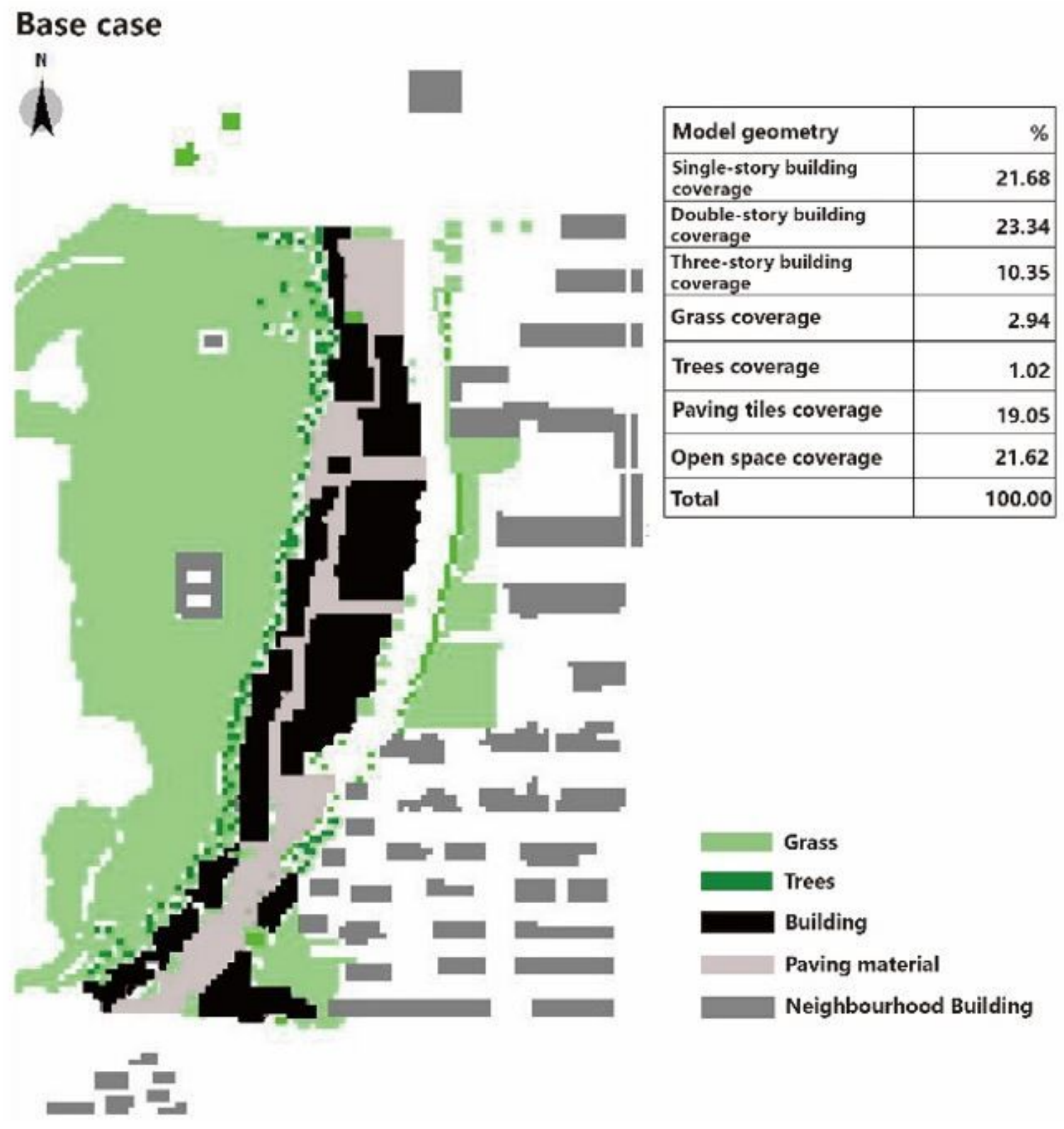

Figure 17

The coverage ratio of different parameters in existing scenario 
Case-1

i
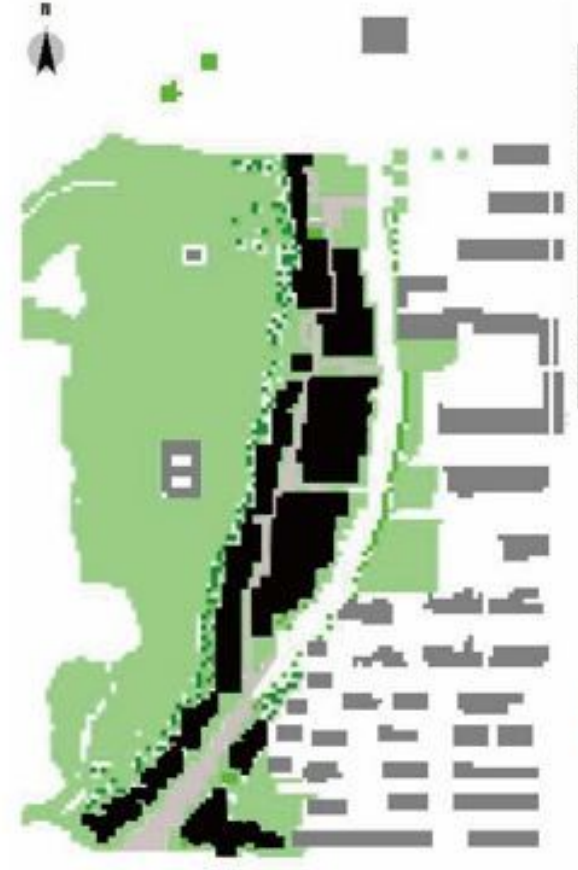

Case-3를

i
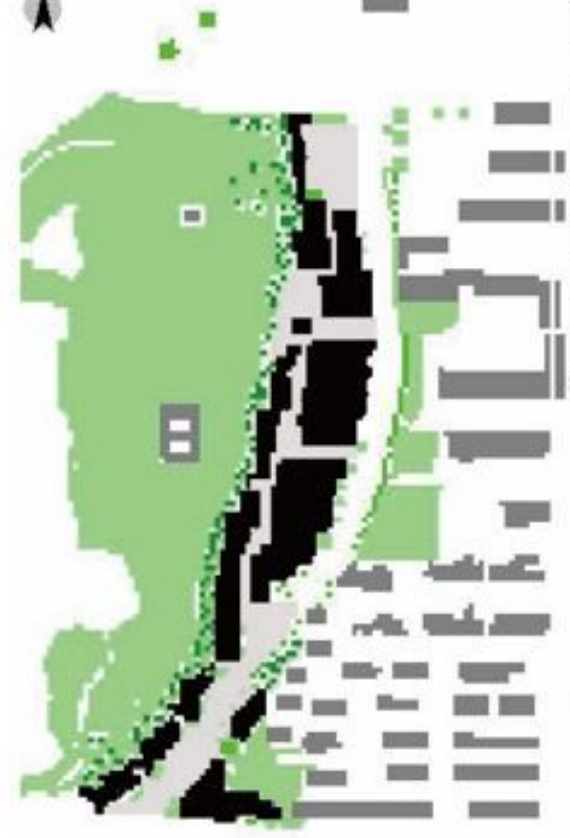

트를
Case-2

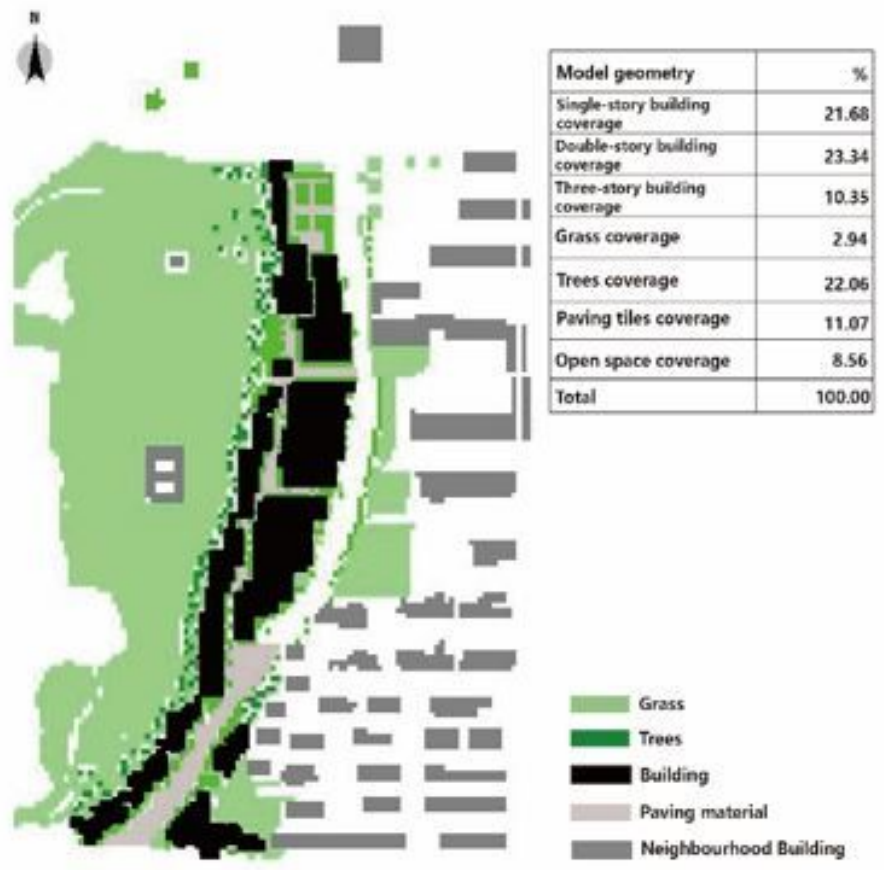

$$
\text { Case-4 }
$$

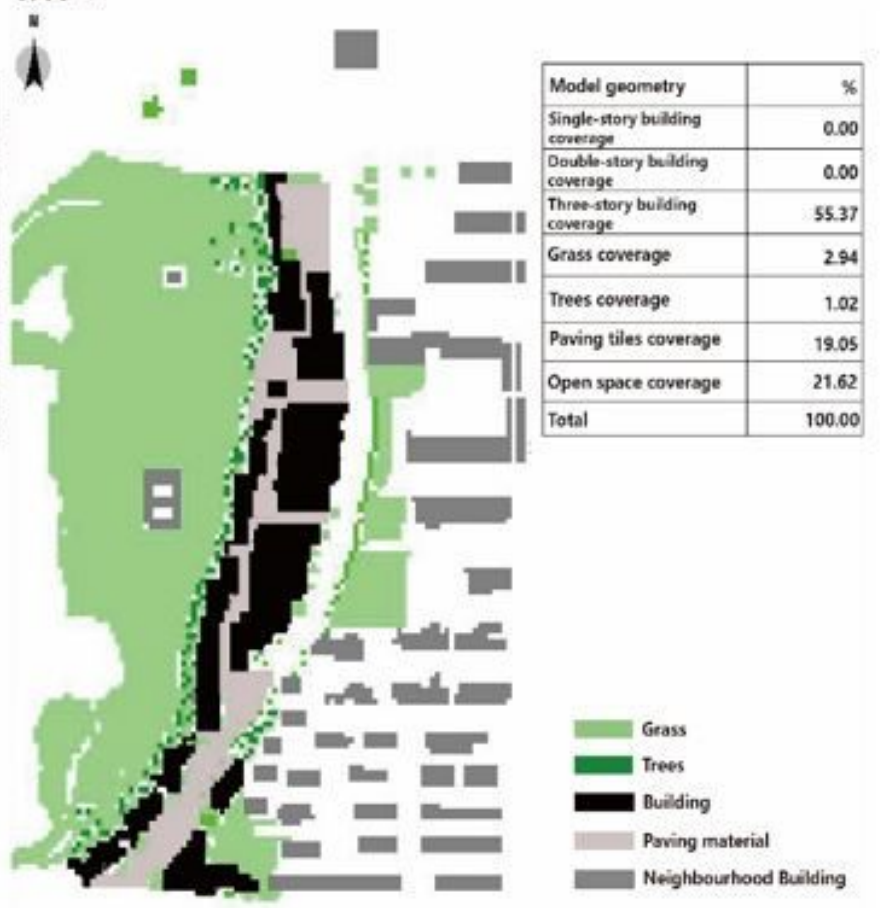

투를

Figure 18

The configuration of different parameters in new cases 

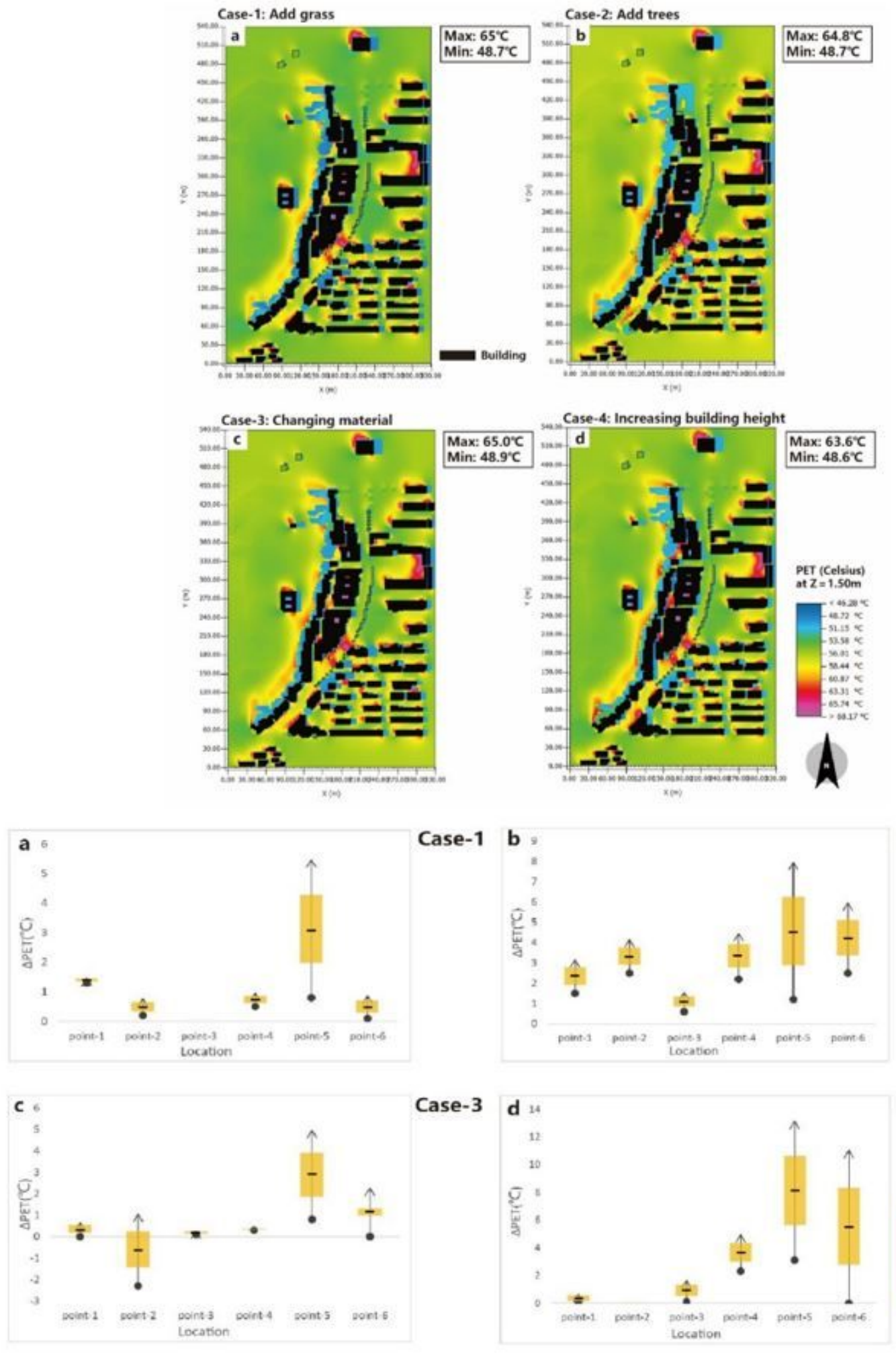

Case-4

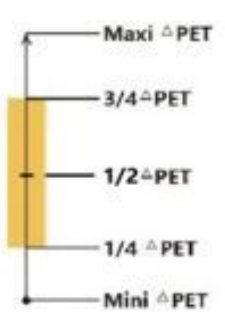

Figure 19

Modification under the new cases at 3:00pm 

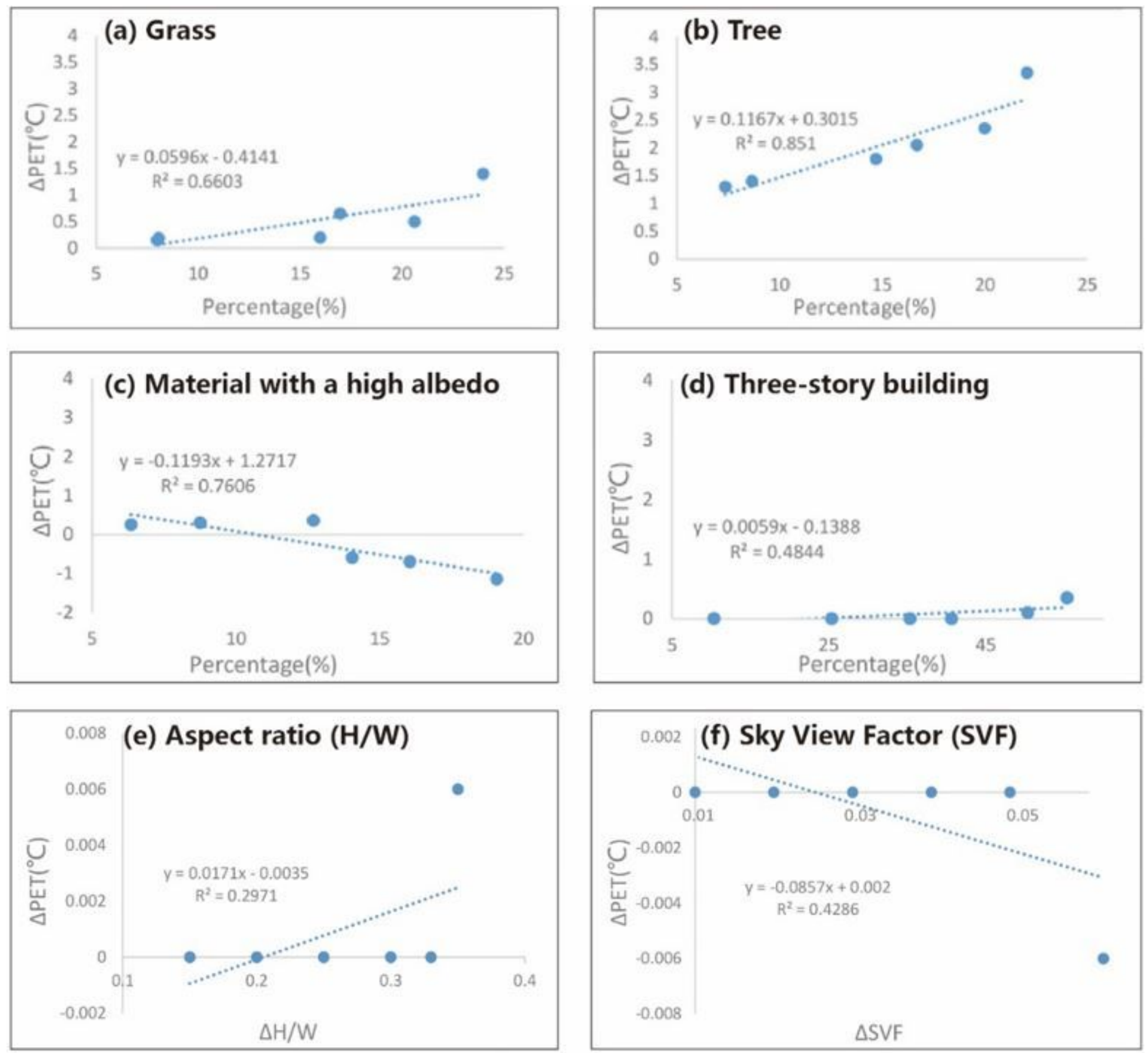

\section{Open Space}

Figure 20

Correlation between cooling effect and different parameters in open space at 3:00pm 

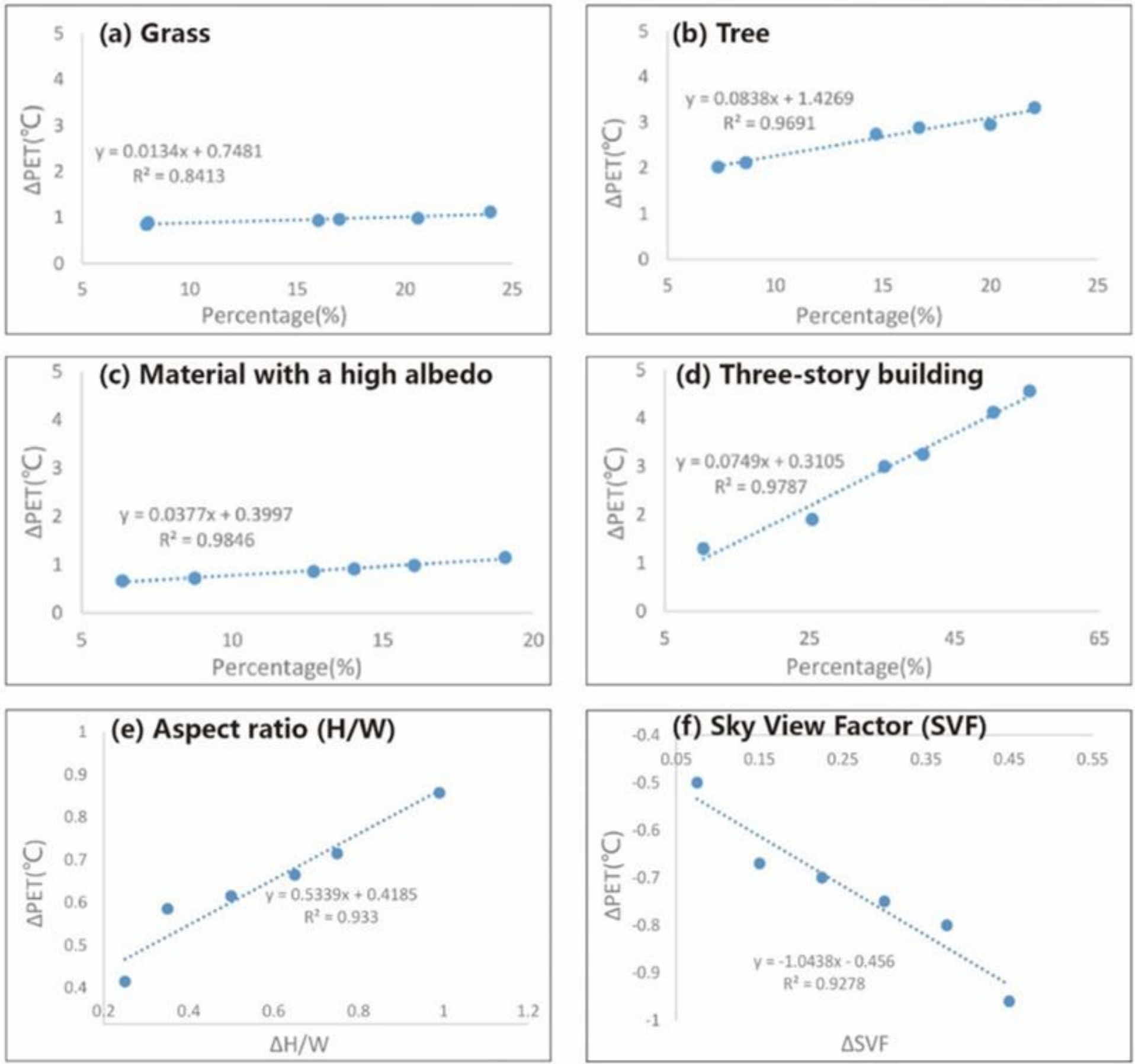

Canyon Space

Figure 21

Correlation between new strategy and thermal safety modification in canyon space at 3:00pm

\section{Supplementary Files}

This is a list of supplementary files associated with this preprint. Click to download.

- table1to7.docx 